\title{
Path Selection for Conformational Interconversions in [2]Catenanes
}

Ronald L. Halterman*, David E. Martyn, Xingang Pan, Diana B. Ha, Michael Frow, Kathryn Haessig

Department of Chemistry and Biochemistry,

University of Oklahoma, 620 Parrington Oval, Norman, OK 73019 
General Procedures: Chemicals and solvents were purchased from Fisher/Acros or Aldrich and used without further purification unless otherwise noted. Reagents 3,5dimethoxy-benzoic acid methyl ester (7), 3,5-bis(bromomethyl)-4'-(1,1'-dimethylethyl)1,1'-biphenyl (11), and BPP34C10 were prepared according to published procedures ${ }^{1,2,3}$. Preparative thin-layer chromatography (TLC) was performed using either $2 \mathrm{~mm}$ or $1 \mathrm{~mm}$ glass-backed sheets pre-coated with silica gel $60 \mathrm{~F}_{254}$ purchased from Fisher Scientific. Column chromatography was carried out using silica gel $60 \mathrm{~F}$ (0.040 to $0.063 \mathrm{~mm}$ particle size). ${ }^{1} \mathrm{H}$ and ${ }^{13} \mathrm{C}$ NMR spectra were recorded on either a Varian 400 or 300 $\mathrm{MHz}$ machine using residual solvent as internal standards: $\mathrm{CHCl}_{3}$ at $7.26 \mathrm{ppm}$, or $\mathrm{C}_{3} \mathrm{H}_{6} \mathrm{O}$ at $2.05 \mathrm{ppm}$. Chemical shifts are denoted in ppm and coupling constants in hertz. Abbreviations for NMR spectra are as follows: $s=$ singlet, $b s=$ broad singlet, $d=$ doublet, $\mathrm{t}=$ triplet, $\mathrm{q}=$ quartet, $\mathrm{m}=$ multiplet. NMR samples were dissolved in $\mathrm{CD}_{3} \mathrm{COCD}_{3}$ or $\mathrm{CDCl}_{3}$ purchased from Cambridge Isotope Laboratories.

(3, 5-Dimethoxy-phenyl)-di-p-tolyl-methanol (8). Magnesium turnings (17.5 g, 0.72 mol) were flushed with nitrogen and freshly distilled THF $(250 \mathrm{ml})$ added followed by 2 drops of 1, 2-dibromoethane to the flask with a condenser. 4-Bromotoluene $(29.5 \mathrm{ml}$, $0.240 \mathrm{~mol}$ ) was added to the mixture slowly and a vigorous exothermic reaction was observed. The reaction was allowed to stir at room temperature overnight. The Grignard reagent was transferred to a solution of 3, 5-dimethoxy-benzoic acid methyl ester (7) (18.8 $\mathrm{g}, 0.096 \mathrm{~mol})$ in THF $(100 \mathrm{ml})$ at room temperature. The mixture was stirred at room temperature overnight. The reaction was quenched with saturated $\mathrm{NH}_{4} \mathrm{Cl}(20 \mathrm{ml})$ 
and extracted with diethyl ether $(3 \times 50 \mathrm{ml})$. The ether layer was washed with water $(3 \times 50$ $\mathrm{ml}$ ) and dried with $\mathrm{MgSO}_{4}$. The filtrate was evaporated providing $34 \mathrm{~g}$ of a yellow oil, which was used without further purification. ${ }^{1} \mathbf{H} \mathbf{N M R}\left(\mathrm{CDCl}_{3}, 300 \mathrm{MHz}\right): \delta 7.05$ (d, $\mathrm{J}=8.2 \mathrm{~Hz}, 4 \mathrm{H}), 6.98(\mathrm{~d}, \mathrm{~J}=8.2,4 \mathrm{H}), 6.38(\mathrm{~d}, \mathrm{~J}=2.3 \mathrm{~Hz}, 2 \mathrm{H}), 6.29(\mathrm{t}, \mathrm{J}=2.3 \mathrm{~Hz}, 1 \mathrm{H}), 3.58$ (s, 6H), 2.29 (s, 6H). ${ }^{13} \mathrm{C}$ NMR $\left(\mathrm{CDCl}_{3}, 75 \mathrm{MHz}\right): \delta 159.6,146.0,139.9,136.6,129.4$, 127.9, 107.5, 99.1, 91.8, 55.1, 21.0. MS (ESI): $\mathrm{m} / \mathrm{z} 371.6\left(\mathrm{M}^{+},+\mathrm{Na}\right)\left(\mathrm{C}_{23} \mathrm{H}_{24} \mathrm{O}_{3}\right.$ requires 348.17)

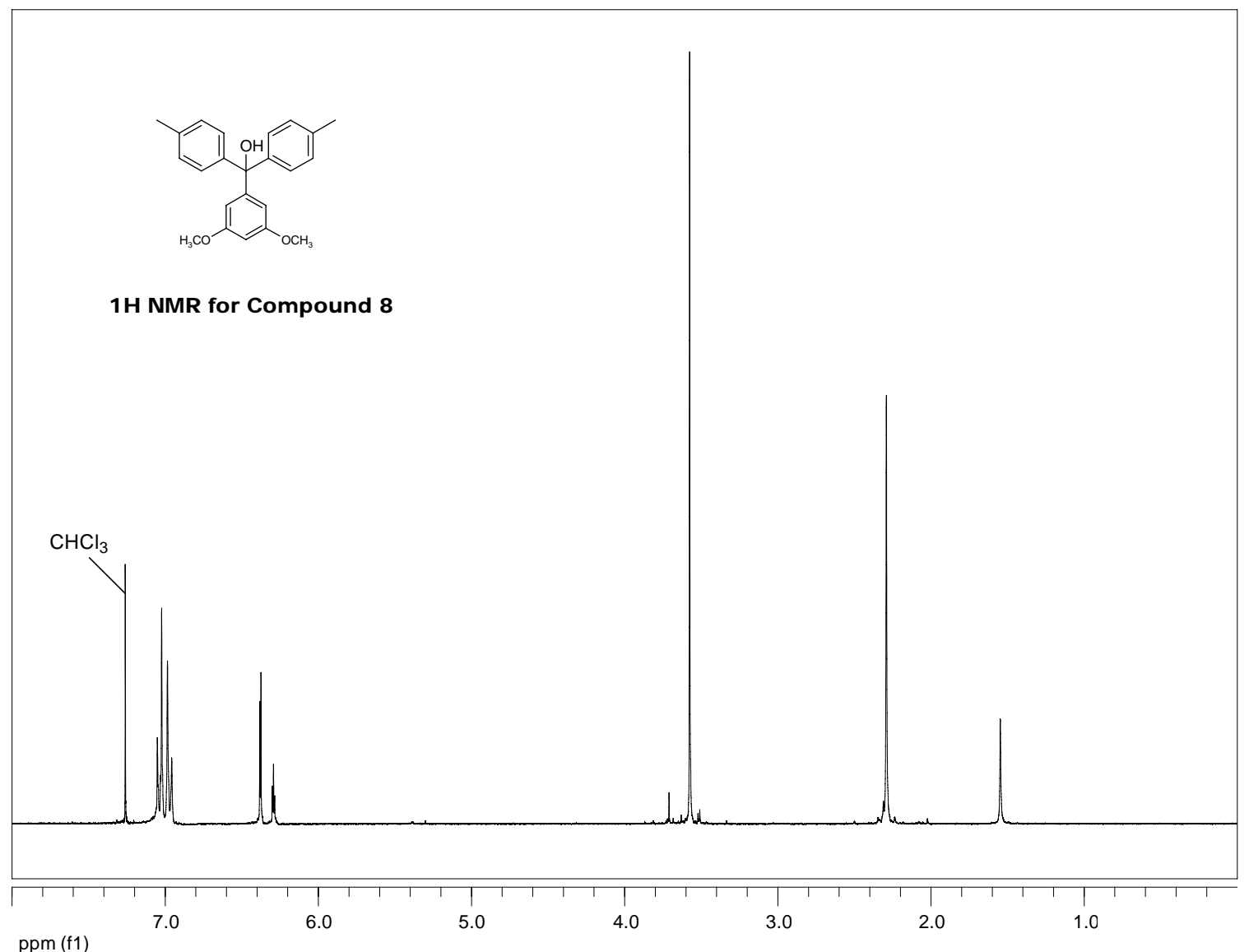

ppm (f1) 


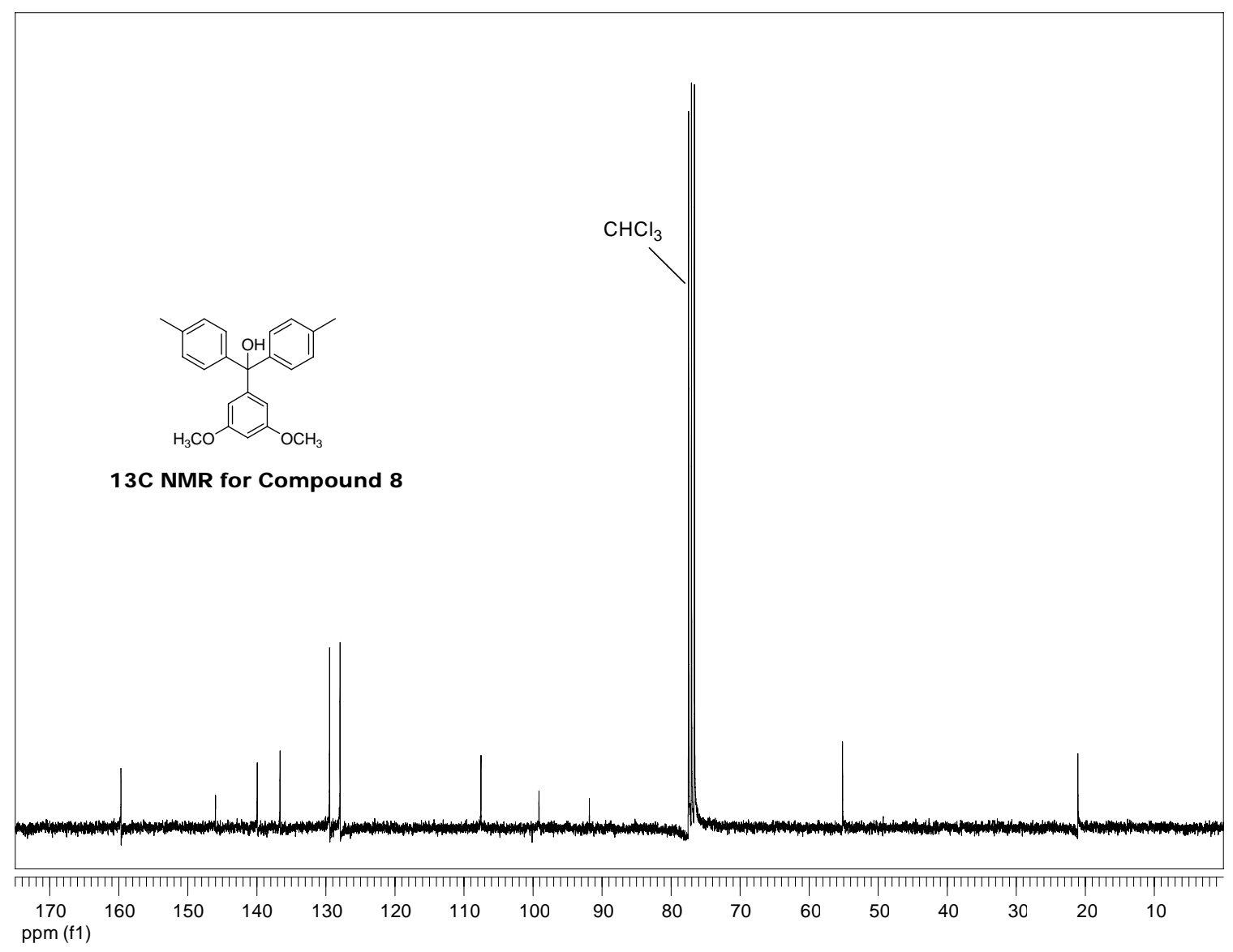

1-Di-p-tolylmethyl-3,5-dimethoxy-benzene (9: Step 1). A mixture of (3, 5-dimethoxyphenyl)-di-p-tolyl-methanol (8) (30 g, $0.086 \mathrm{~mol}), 5 \%$ palladium/carbon (1.5 g), $\mathrm{CH}_{3} \mathrm{OH}$ $(30 \mathrm{ml}), \mathrm{CH}_{3} \mathrm{COOH}(1 \mathrm{ml})$ was stirred at room temperature under a balloon of hydrogen for one week. The catalyst was filtered though a pad of Celite and the filtrate was evaporated. The residue was purified by flash chromatography. Petroleum ether/methylene chloride (1:1) gave a yellow oil (16 g, 56\%). ${ }^{\mathbf{1}} \mathbf{H} \mathbf{~ N M R}\left(\mathrm{CDCl}_{3}\right.$, 300MHz): $\delta 7.08$ (d, J=8.5 Hz, 4H), 7.00 (d, J=8.2 Hz, 4H), 6.31 (t, J=2.3 Hz, 1H), 6.27 $(\mathrm{d}, \mathrm{J}=2.1 \mathrm{~Hz}, 2 \mathrm{H}), 5.39$ (s, 1H), $3.71(\mathrm{~s}, 6 \mathrm{H}), 2.31(\mathrm{~s}, 6 \mathrm{H}) .{ }^{13} \mathrm{C} \mathbf{N M R}\left(\mathrm{CDCl}_{3}, 75 \mathrm{MHz}\right)$ : $\delta 160.6,146.8,140.9,135.8,129.2,129.0,107.9,97.9,56.3,55.3,21.1$. MS (ESI): m/z $355.2\left(\mathrm{M}^{+},+\mathrm{Na}\right)\left(\mathrm{C}_{23} \mathrm{H}_{24} \mathrm{O}_{2}\right.$ requires 332.18) 
Supporting Information

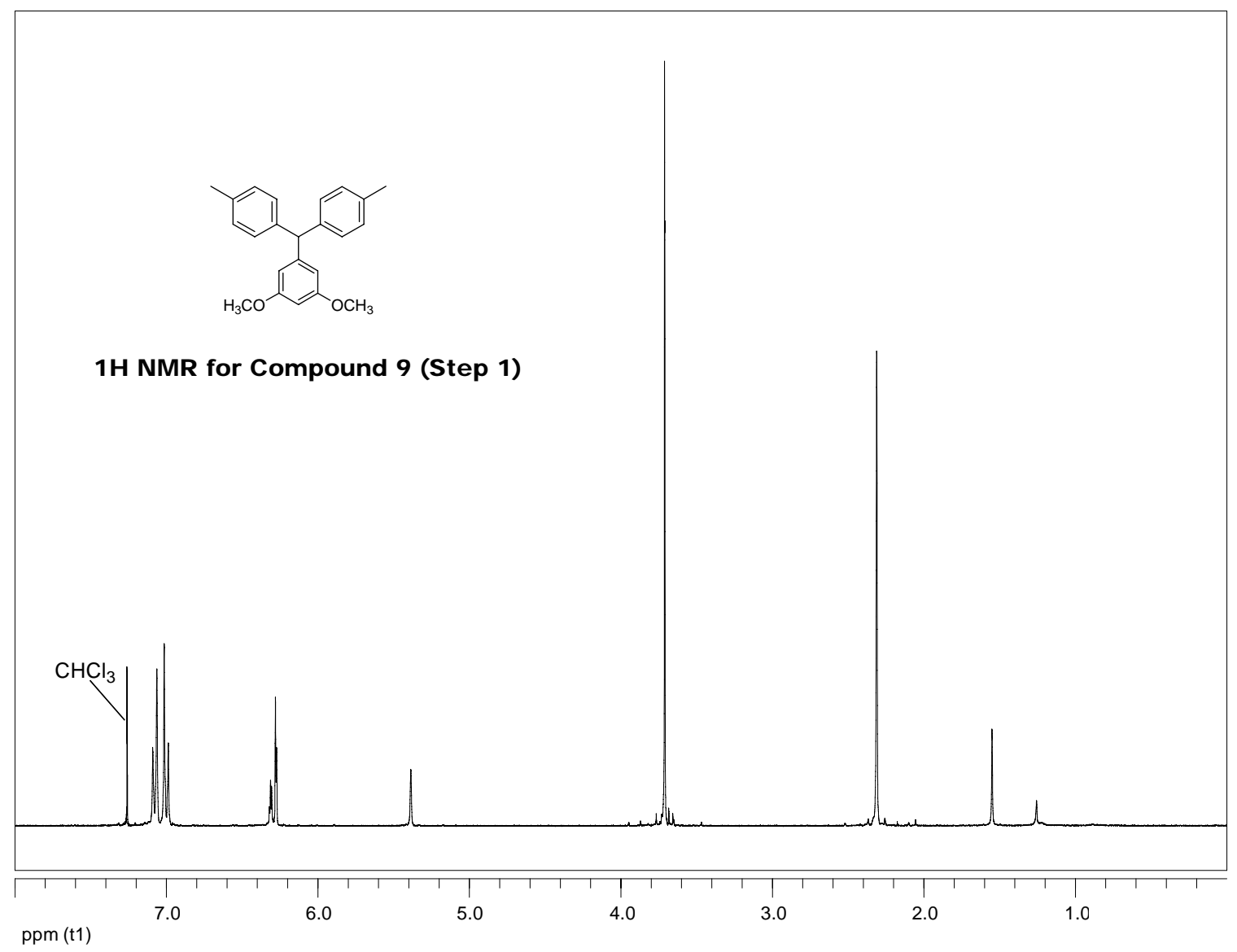




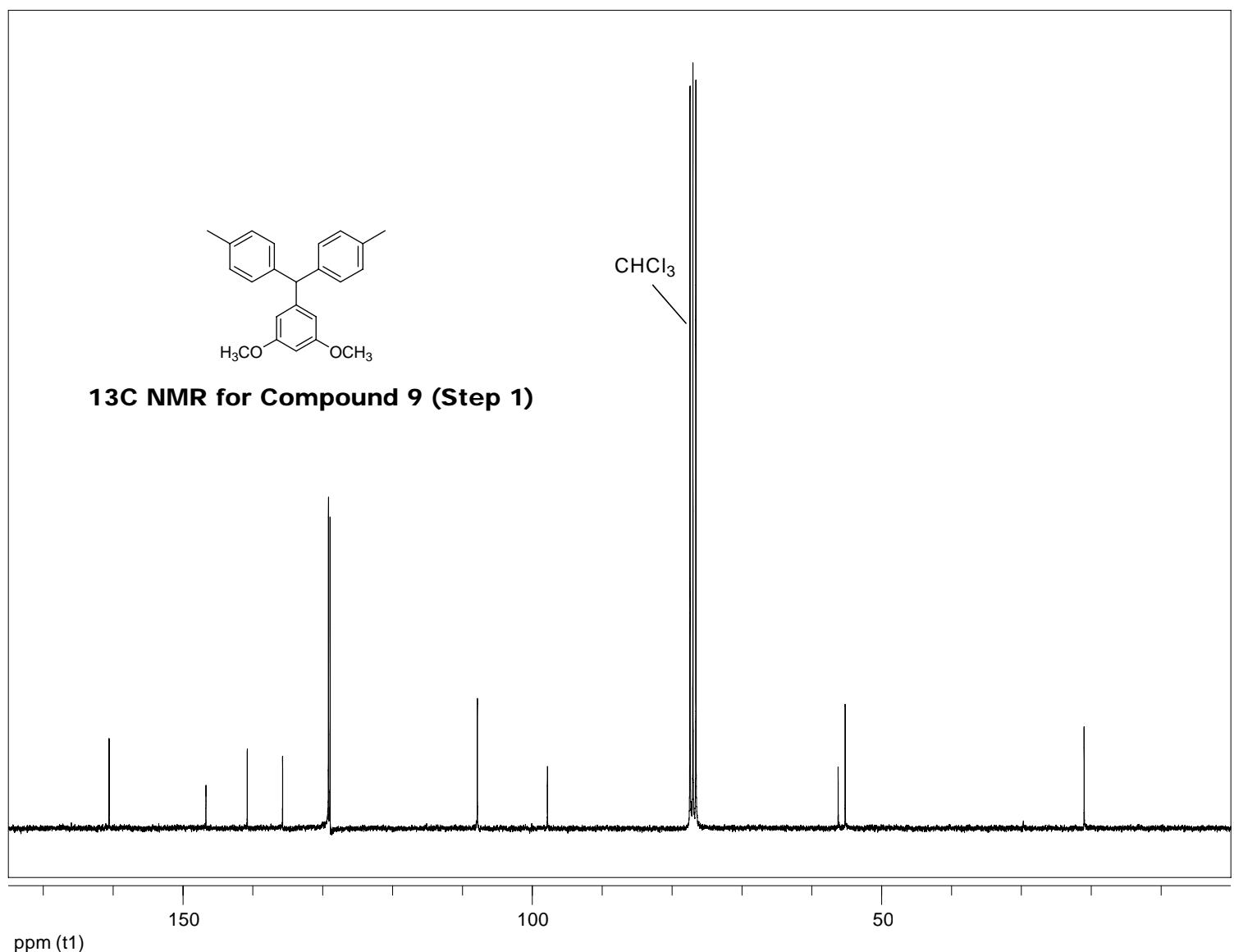

5-Di-p-tolylmethyl-benzene-1,3-diol (9: Step 2). To a solution of 1-Di-p-tolylmethyl3,5-dimethoxy-benzene $(7.0 \mathrm{~g}, 0.021 \mathrm{~mol})$ in methylene chloride $(80 \mathrm{ml})$, Boron tribromide $(4.8 \mathrm{ml}, 0.0504 \mathrm{~mol})$ were added at $-78^{\circ} \mathrm{C}$. The mixture was allowed to warm to room temperature for $20 \mathrm{hrs}$. The reaction was quenched with methanol $(80 \mathrm{ml})$ and ice $(80 \mathrm{~g})$. The mixture was extracted with methylene chloride $(3 \times 50 \mathrm{ml})$ and the organic layer was washed with water $(3 \times 50 \mathrm{ml})$. The extract was dried with $\mathrm{MgSO}_{4}$, filtered and the filtrate was evaporated to give an orange paste $(6.3 \mathrm{~g}, 98 \%) .{ }^{\mathbf{1}} \mathbf{H} \mathbf{~ N M R}\left(\mathrm{CDCl}_{3}\right.$, 300MHz): $\delta 7.09$ (d, J=8.2 Hz, 4H), 7.00 (d, J=8.2 Hz, 4H), 6.19 (t, J=2.3 Hz, 1H), 6.14 $(\mathrm{d}, \mathrm{J}=2.3 \mathrm{~Hz}, 2 \mathrm{H}), 5.33(\mathrm{~s}, 1 \mathrm{H}), 2.32(\mathrm{~s}, 6 \mathrm{H}) .{ }^{13} \mathrm{C} \mathbf{N M R}\left(\mathrm{CDCl}_{3}, 75 \mathrm{MHz}\right): \delta 156.5,147.5$, 
140.5, 135.9, 129.2, 129.0, 109.2, 100.7, 55.7, 21.0. MS (ESI): $\mathrm{m} / \mathrm{z} 327.5\left(\mathrm{M}^{+},+\mathrm{Na}\right)$ $\left(\mathrm{C}_{21} \mathrm{H}_{20} \mathrm{O}_{2}\right.$ requires 304.15)

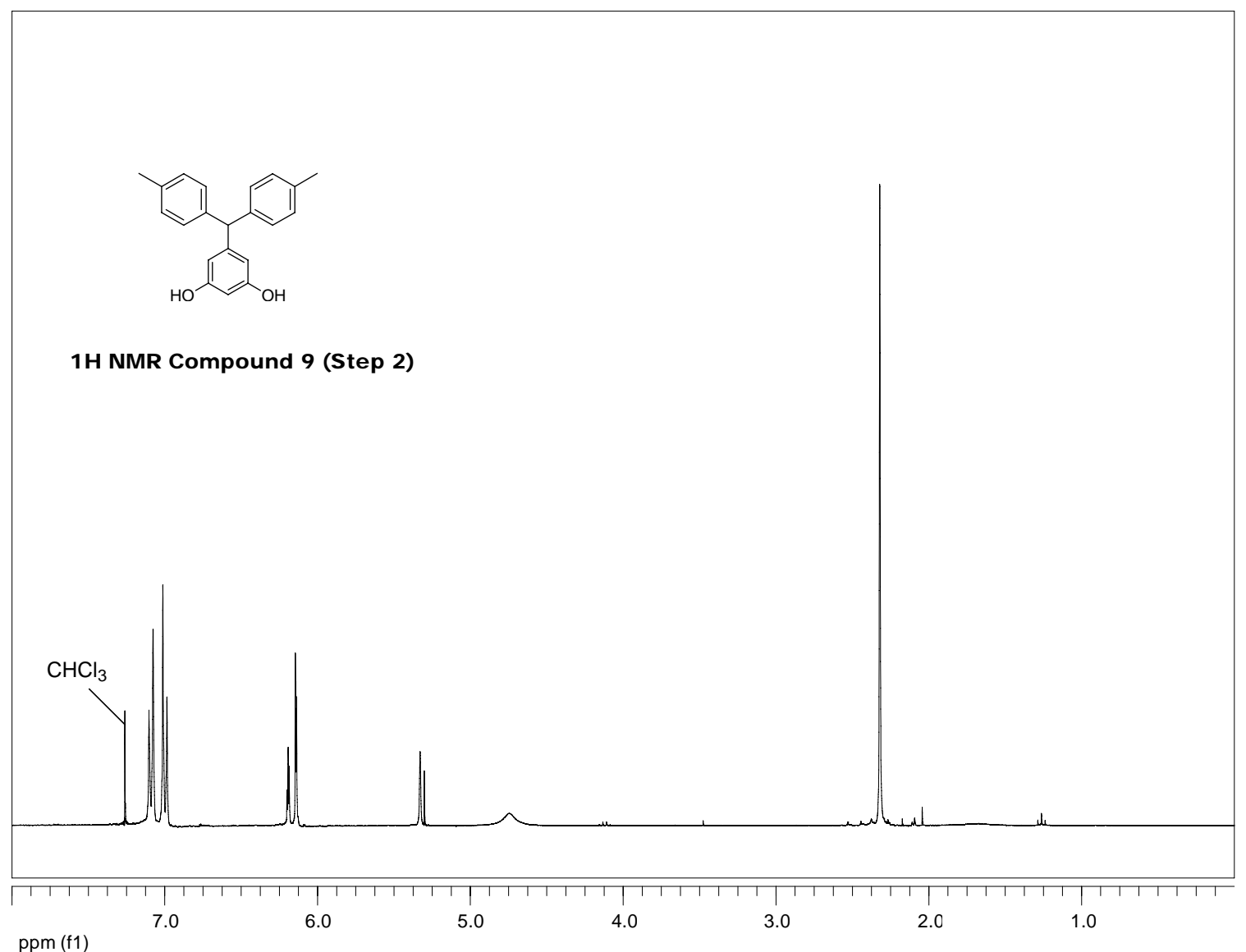

ppm (f1) 


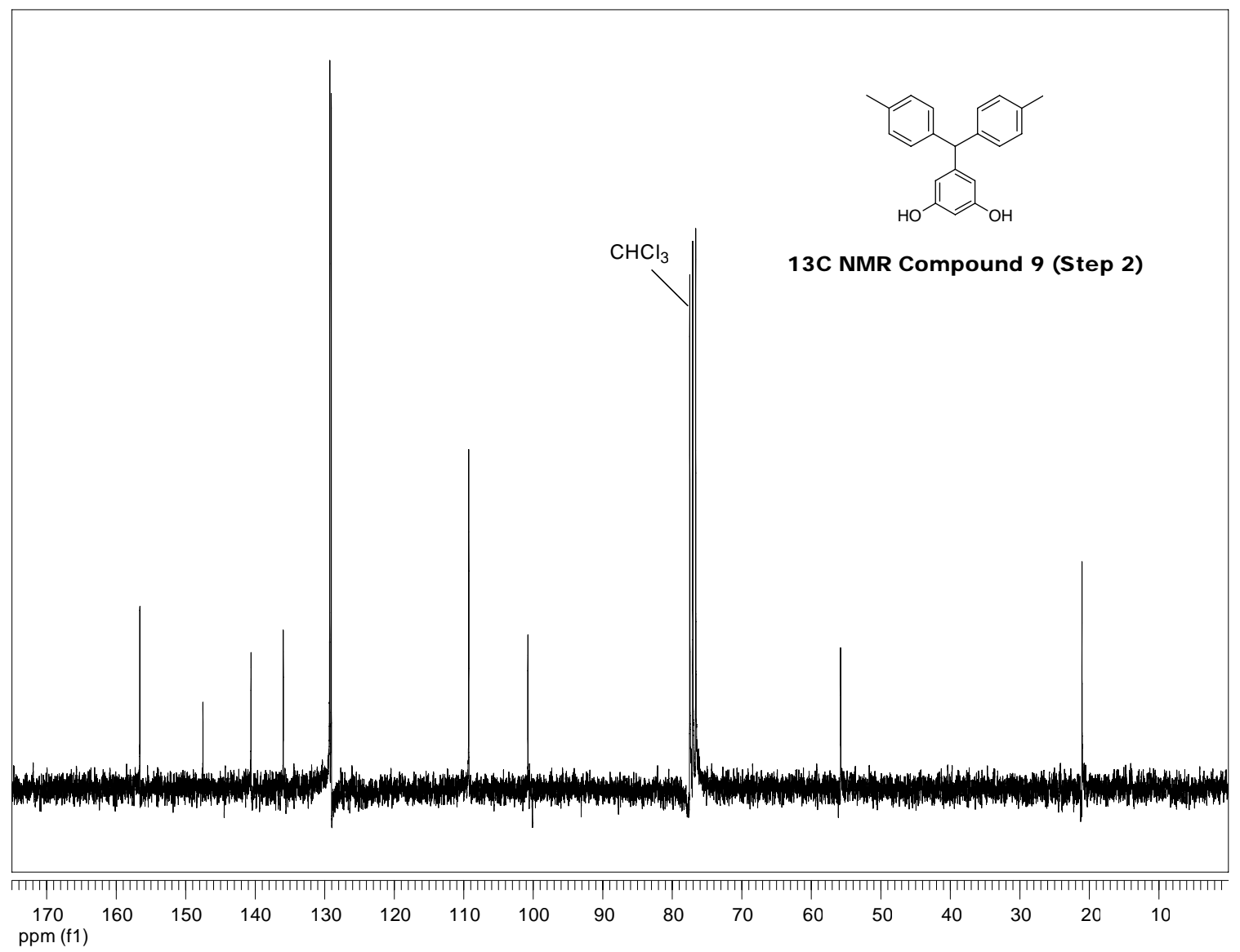

1,3-bis(2-hydroxyethoxy)benzene (13a). Sodium hydroxide (12.00 g, $300 \mathrm{mmol}$ ) was dissolved in a solution of ethanol $(150 \mathrm{ml})$ and water $(50 \mathrm{ml})$. To this solution was added 1,3-dihydroxybenzene $(11.01 \mathrm{~g}, 100 \mathrm{mmol})$ previously dissolved in ethanol $(150 \mathrm{ml})$ creating a dark red solution that was allowed to stir for 10 minutes. 2-Chloroethanol (24.15 g, $300 \mathrm{mmol}$ ) was added to the stirring solution after which the reaction mixture was refluxed 4 days. Precipitate formed in the reaction vessel and the solution became ruby red in color. After cooling to room temperature, the solvent was removed in vacuo leaving a red solid that was dissolved in EtOAc $(100 \mathrm{ml})$ and washed with water (200mL). The water was extracted twice more with EtOAc $(100 \mathrm{ml})$. After combining, the organic fractions were washed with brine $(100 \mathrm{ml})$ and dried over $\mathrm{MgSO}_{4}$. Removal 
of solvent yielded $16.9 \mathrm{~g}$ ( $85 \%$ yield) of product that was utilized without further purification. ${ }^{1} \mathbf{H}$ NMR $\left(\mathrm{CDCl}_{3}, 300 \mathrm{MHz}\right): \delta 7.19(\mathrm{t}, \mathrm{J}=7.9,1 \mathrm{H}), 6.56(\mathrm{~d}, \mathrm{~J}=2.4 \mathrm{~Hz}, 1 \mathrm{H})$, $6.51(\mathrm{~m}, 2 \mathrm{H}), 4.07(\mathrm{~m}, 4 \mathrm{H}), 3.96(\mathrm{~m}, 4 \mathrm{H}), 2.01(\mathrm{~s}, 2 \mathrm{H}) .{ }^{13} \mathbf{C} \mathbf{~ N M R}\left(\mathrm{CDCl}_{3}, 75 \mathrm{MHz}\right): \delta$ 159.8, 130.0, 107.1, 101.7, 69.2, 61.4 MS (ESI): $\mathrm{m} / \mathrm{z} 198.1\left(\mathrm{M}^{+}\right)\left(\mathrm{C}_{10} \mathrm{H}_{14} \mathrm{O}_{4}\right.$ requires 198.22).

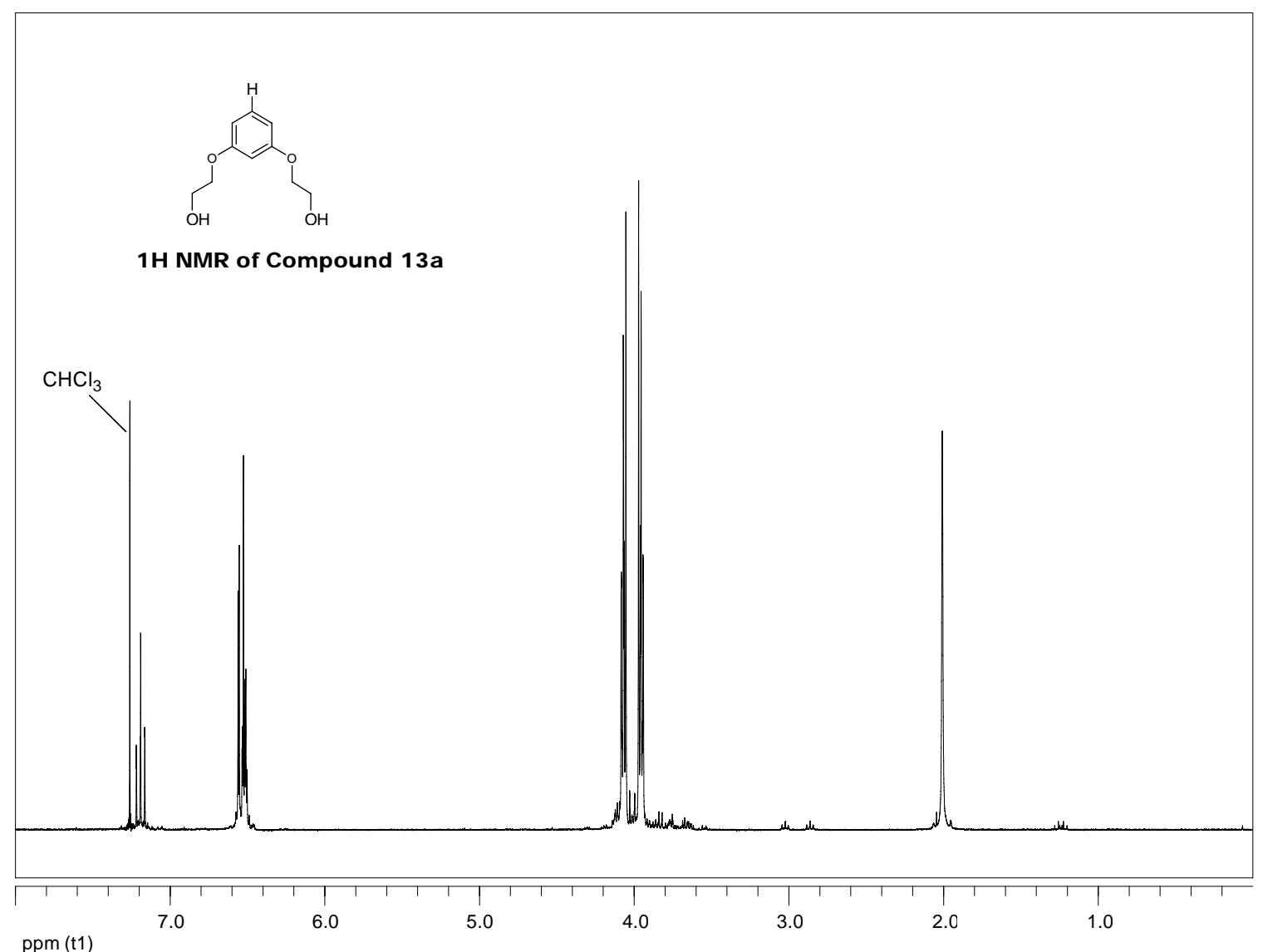




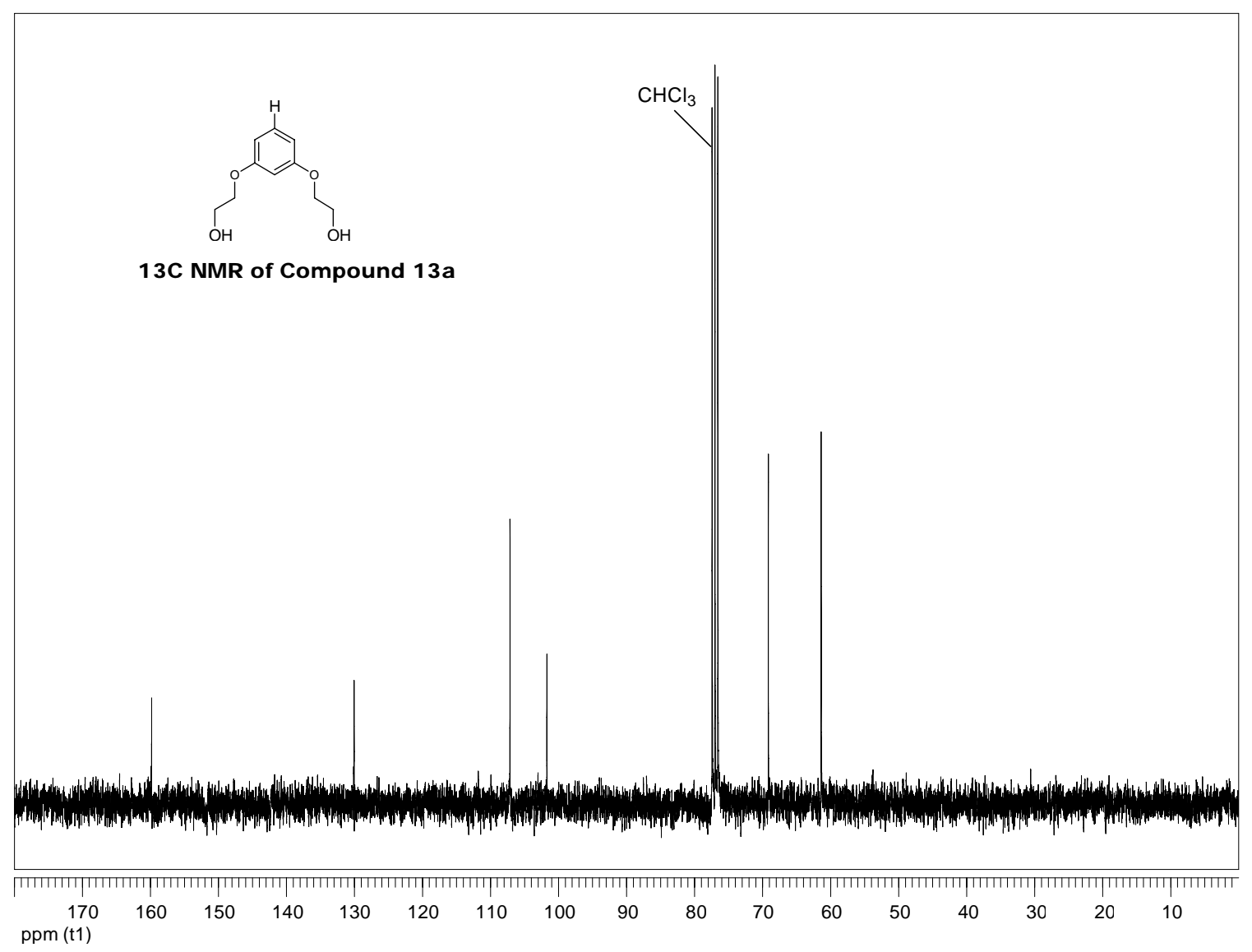

1,3-Bis(2-bromoethoxy)benzene (14a). $\mathrm{PPh}_{3}(30 \mathrm{~g}, 114.3 \mathrm{mmol})$ was added to $\mathrm{CH}_{3} \mathrm{CN}$ $(100 \mathrm{ml})$ and cooled to $-10^{\circ} \mathrm{C} . \mathrm{Br}_{2}(18.27 \mathrm{~g}, 159.8 \mathrm{mmol})$ dissolved in $\mathrm{CH}_{3} \mathrm{CN}(20 \mathrm{ml})$ was slowly added to the stirring $\mathrm{PPh}_{3}$ mixture so as not to exceed $0^{\circ} \mathrm{C}$. The mixture was allowed to warm to room temperature after the addition was complete. 1,3-Bis(2hydroxyethoxy)benzene (13a) $(9.90 \mathrm{~g}, 50 \mathrm{mmol})$ dissolved in $\mathrm{CH}_{3} \mathrm{CN}$ was added to the mixture and allowed to stir overnight. Solvent was removed in vacuo and the crude product purified via column chromatography using $\mathrm{CH}_{2} \mathrm{Cl}_{2}$ to elute. The product was obtained in $83.7 \%$ yield $(22.38 \mathrm{~g})$ and analysis by NMR showed it to be pure. ${ }^{\mathbf{1}} \mathbf{H}$ NMR $\left(\mathrm{CDCl}_{3}, 300 \mathrm{MHz}\right): \delta 7.20(\mathrm{t}, J=8.2 \mathrm{~Hz}, 1 \mathrm{H}), 6.56(\mathrm{~d}, J=2.4 \mathrm{~Hz}, 1 \mathrm{H}), 6.54-6.48(\mathrm{~m}, 2 \mathrm{H})$, $4.28(\mathrm{t}, J=6.3 \mathrm{~Hz}, 4 \mathrm{H}), 3.63(\mathrm{t}, J=6.3 \mathrm{~Hz}, 4 \mathrm{H}) .{ }^{13} \mathrm{C} \mathbf{N M R}\left(\mathrm{CDCl}_{3}, 75 \mathrm{MHz}\right): \delta 159.3$, 
130.2, 107.5, 102.1, 67.8, 29.0. MS (EI): m/z $324.0\left(\mathrm{M}^{+}\right), 243.1,216.1,137.2,109.2$

$\left(\mathrm{C}_{10} \mathrm{H}_{12} \mathrm{O}_{2} \mathrm{Br}_{2}\right.$ requires 324.01).

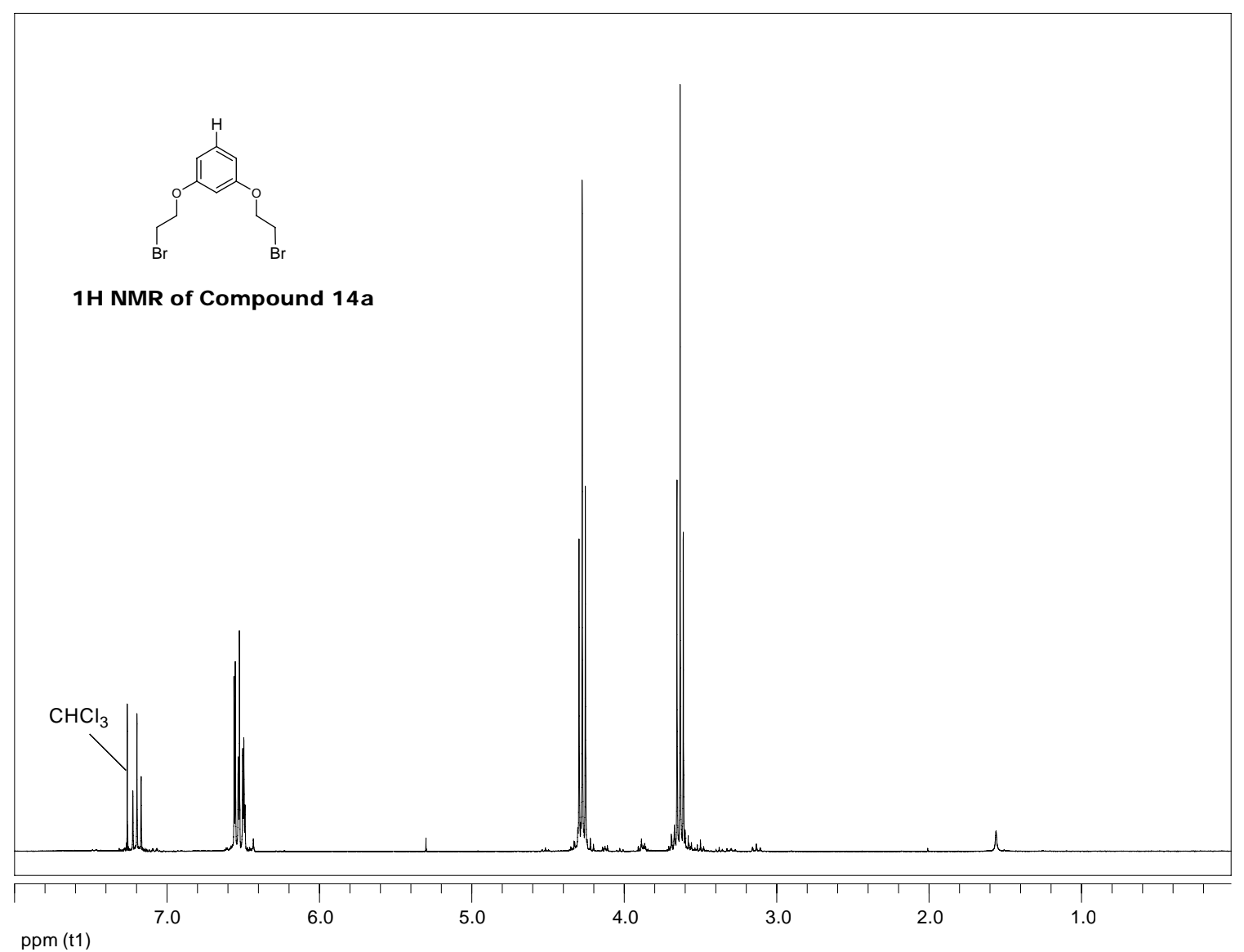

ppm (t1) 


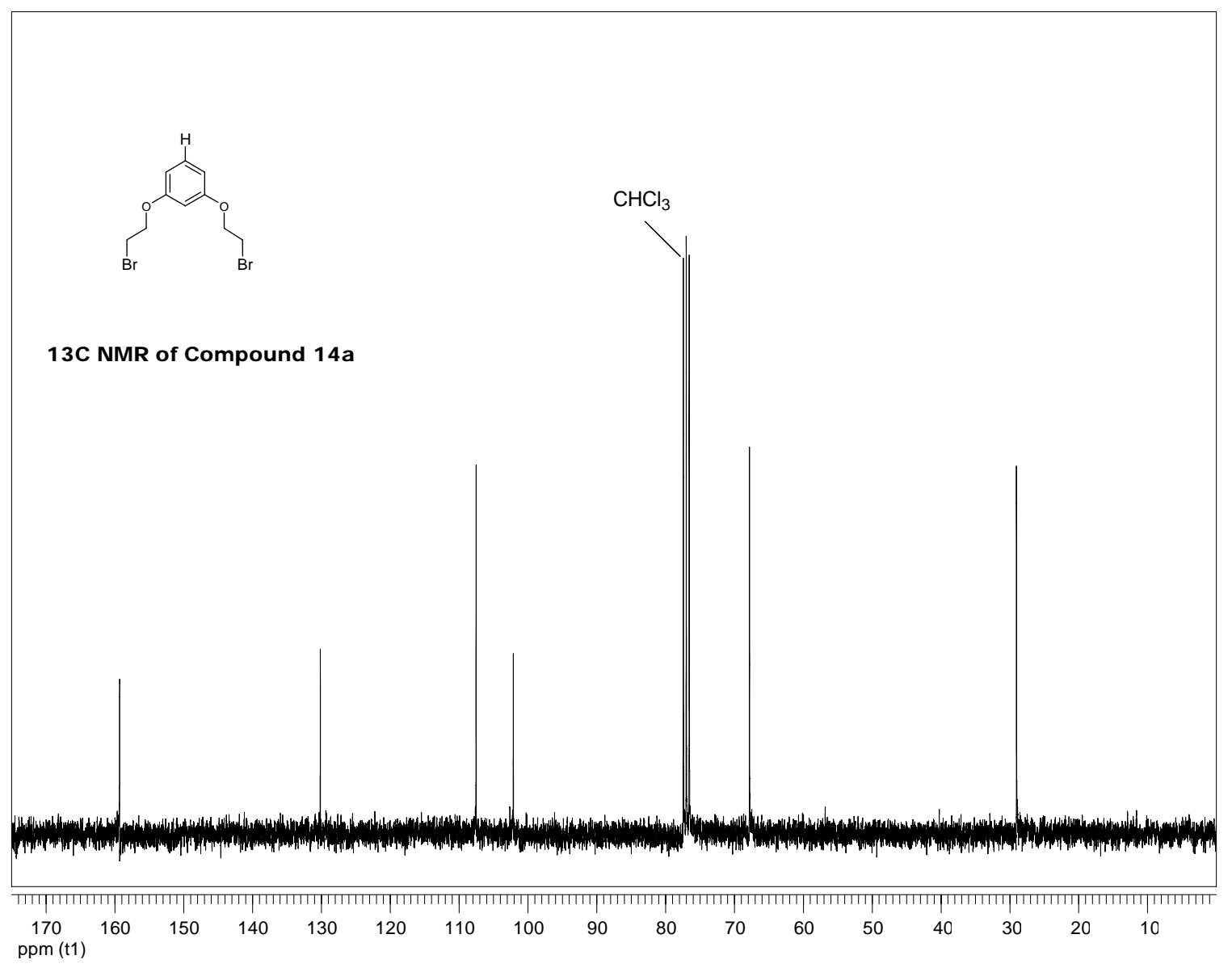

\section{1,3-Bis(2-(4,4'-dipyridinium)ethoxy)benzene dihexafluorophosphate (15a). 1,3-Di(2-}

bromoethoxy)benzene (14a) (11.30 g, $27.7 \mathrm{mmol})$ and 4,4-dipyridyl (17.30 g, 110.8

mmol) were added to $200 \mathrm{ml}$ of $\mathrm{CH}_{3} \mathrm{CN}$. This solution was stirred at $70^{\circ} \mathrm{C}$ for two days.

After cooling to room temperature the solvent was removed in vacuo leaving a brown

solid. Water was added and upon heating the solid dissolved producing a brown solution.

Addition of $\mathrm{NH}_{4} \mathrm{PF}_{6}(11 \mathrm{~g})$ produced a brown oil which was isolated and washed with

$\mathrm{CHCl}_{3}(3 \times 20 \mathrm{ml})$ leaving a yellow oil which was then dissolved in $\mathrm{CH}_{3} \mathrm{CN}$ and dried with $\mathrm{MgSO}_{4}$. Removal of the solvent in vacuo left $23.5 \mathrm{~g}(98.7 \%)$ of yellow crystals. ${ }^{1} \mathbf{H}$

NMR $\left(\mathrm{C}_{3} \mathrm{D}_{6} \mathrm{O}, 300 \mathrm{MHz}\right): \delta 9.33(\mathrm{~d}, J=7.2 \mathrm{~Hz}, 4 \mathrm{H}), 8.87$ (dd, J=7.2 Hz, $\left.1.7 \mathrm{~Hz}, 4 \mathrm{H}\right)$,

$7.98(\mathrm{dd}, J=4.5 \mathrm{~Hz}, 1.7 \mathrm{~Hz}, 4 \mathrm{H}), 7.18$ (t, $J=8.2 \mathrm{~Hz}, 1 \mathrm{H}), 6.66$ (t, $J=2.3 \mathrm{~Hz}, 1 \mathrm{H}), 6.60$ (dd, 
$J=8.2 \mathrm{~Hz}, 2.4 \mathrm{~Hz}, 2 \mathrm{H}), 5.31(\mathrm{t}, J=4.8 \mathrm{~Hz}, 4 \mathrm{H}), 4.66(\mathrm{t}, J=5.1,4 \mathrm{~Hz}){ }^{13} \mathbf{C} \mathbf{N M R}\left(\mathrm{C}_{3} \mathrm{D}_{6} \mathrm{O}\right.$, 75MHz): $\delta 160.9,156.3,153.1,148.0,143.0,132.1,127.6,123.6,109.5,103.8,68.1$, 62.6. $\mathrm{MS}$ (ESI): $\mathrm{m} / \mathrm{z} 238.1\left(\mathrm{M}^{2+}\right), 621.3\left(\mathrm{M}^{+},+\mathrm{PF}_{6}\right)\left(\mathrm{C}_{30} \mathrm{H}_{28} \mathrm{O}_{2} \mathrm{~N}_{4}{ }^{2+}\right.$ requires 476.6)

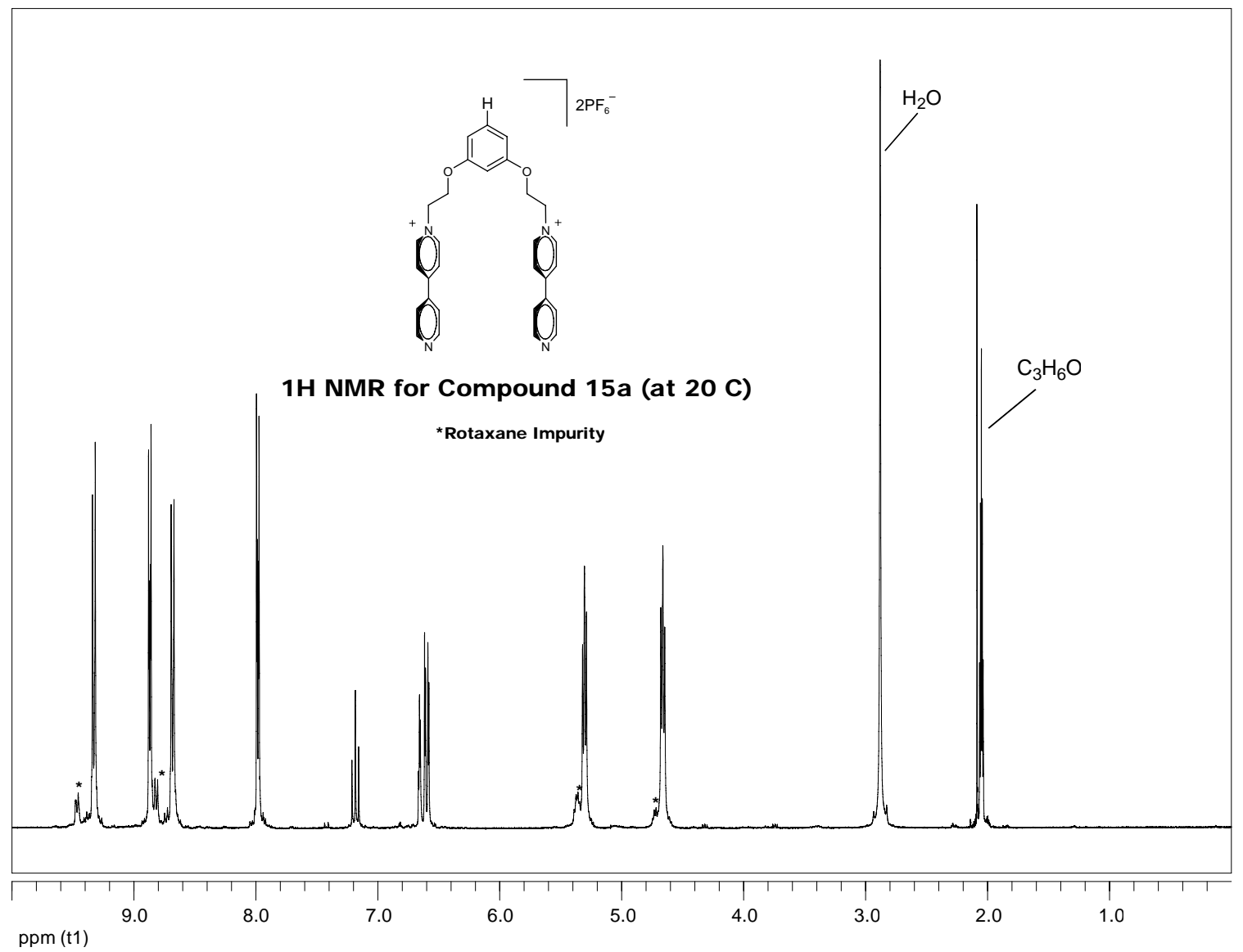




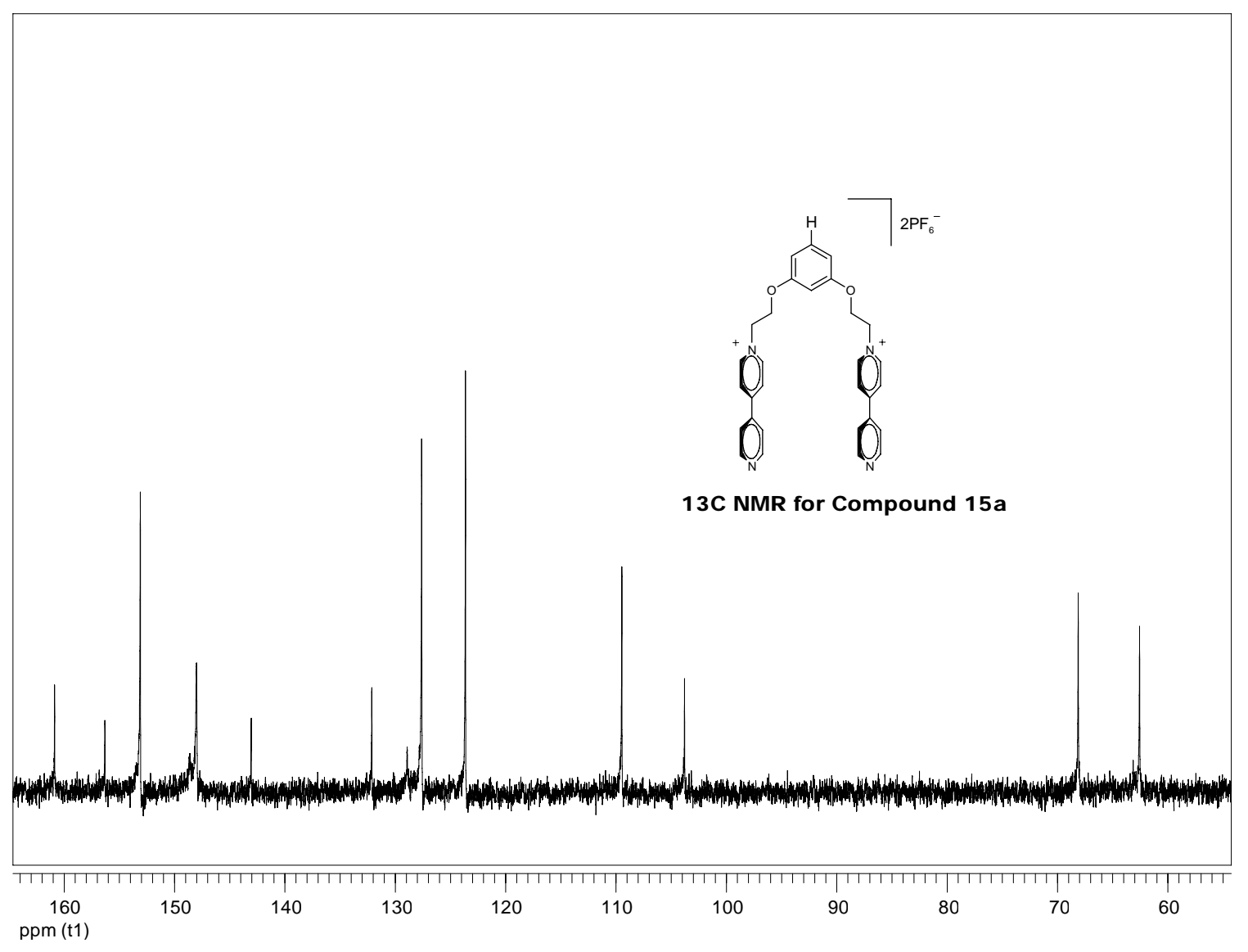

2-(3-Di-p-tolylmethyl-5-(2-hydroxy-ethoxy)-phenoxy)-ethanol (13b). To a solution of 5-Di-p-tolylmethyl-benzene-1,3-diol (9) (3.2 g, $0.0105 \mathrm{~mol})$ in ethanol (20 ml) was added a solution containing $\mathrm{NaOH}(1.26 \mathrm{~g}, 0.0315 \mathrm{~mol})$, ethanol $(20 \mathrm{ml})$, water $(7 \mathrm{ml})$. The mixture was stirred at room temperature for 10 minutes. 2-Chloroethanol $(2.1 \mathrm{ml}, 0.0315$ mol) was added at room temperature and the reaction mixture was stirred at reflux for 4 days, then allowed to cool and concentrated under diminished pressure. The residue was extract with ethyl acetate $(3 \times 30 \mathrm{ml})$. The organic layer was washed with water $(3 \times 30 \mathrm{ml})$ and brines $(3 \times 30 \mathrm{ml})$. The extract was dried with $\mathrm{MgSO}_{4}$, filtered and the filtrate was evaporated to give a grey solid (3.85 g, 93\%). ${ }^{1} \mathbf{H}$ NMR $\left(\mathrm{CDCl}_{3}, 300 \mathrm{MHz}\right): \delta 7.08(\mathrm{~d}$, $\mathrm{J}=7.9 \mathrm{~Hz}, 4 \mathrm{H}), 7.00(\mathrm{~d}, \mathrm{~J}=8.2 \mathrm{~Hz}, 4 \mathrm{H}), 6.34(\mathrm{t}, \mathrm{J}=2.3 \mathrm{~Hz}, 1 \mathrm{H}), 6.31$ (d, J=2.1 Hz, 2H), 5.38 
(s, 1H), 3.96 (td, J=4.7 Hz, 1.8 Hz, 4H), 3.88 (td, J=4.7 Hz, $1.8 \mathrm{~Hz}, 4 \mathrm{H}), 2.32(\mathrm{~s}, 6 \mathrm{H}) .{ }^{13} \mathrm{C}$ NMR $\left(\mathrm{CDCl}_{3}, 75 \mathrm{MHz}\right): \delta 159.6,147.0,140.6,135.8,129.1,129.0,108.7,99.0,69.0$, 61.3, 56.1, 21.0. MS (ESI): m/z $415.7\left(\mathrm{M}^{+},+\mathrm{Na}\right)\left(\mathrm{C}_{25} \mathrm{H}_{28} \mathrm{O}_{4}\right.$ requires 392.20).

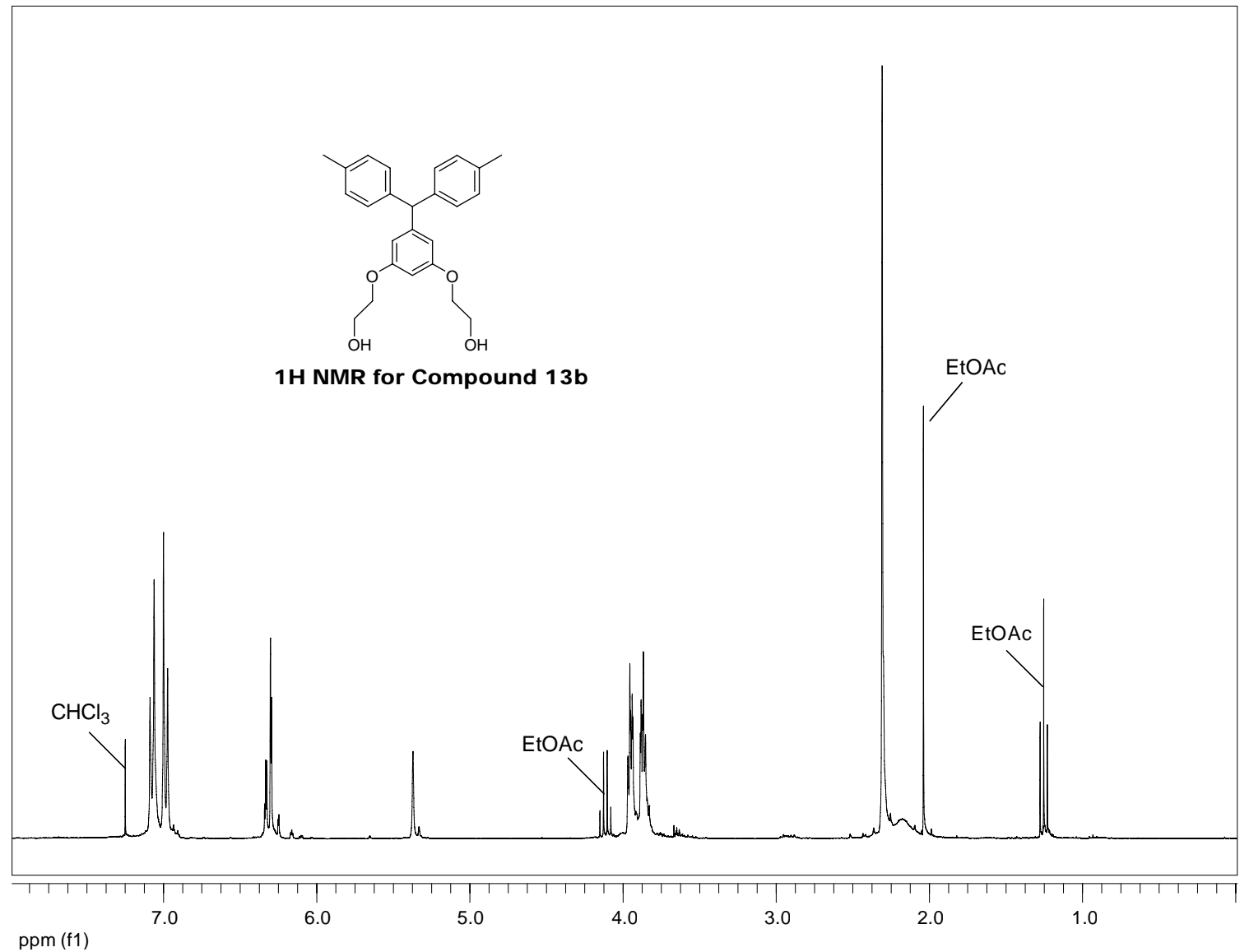




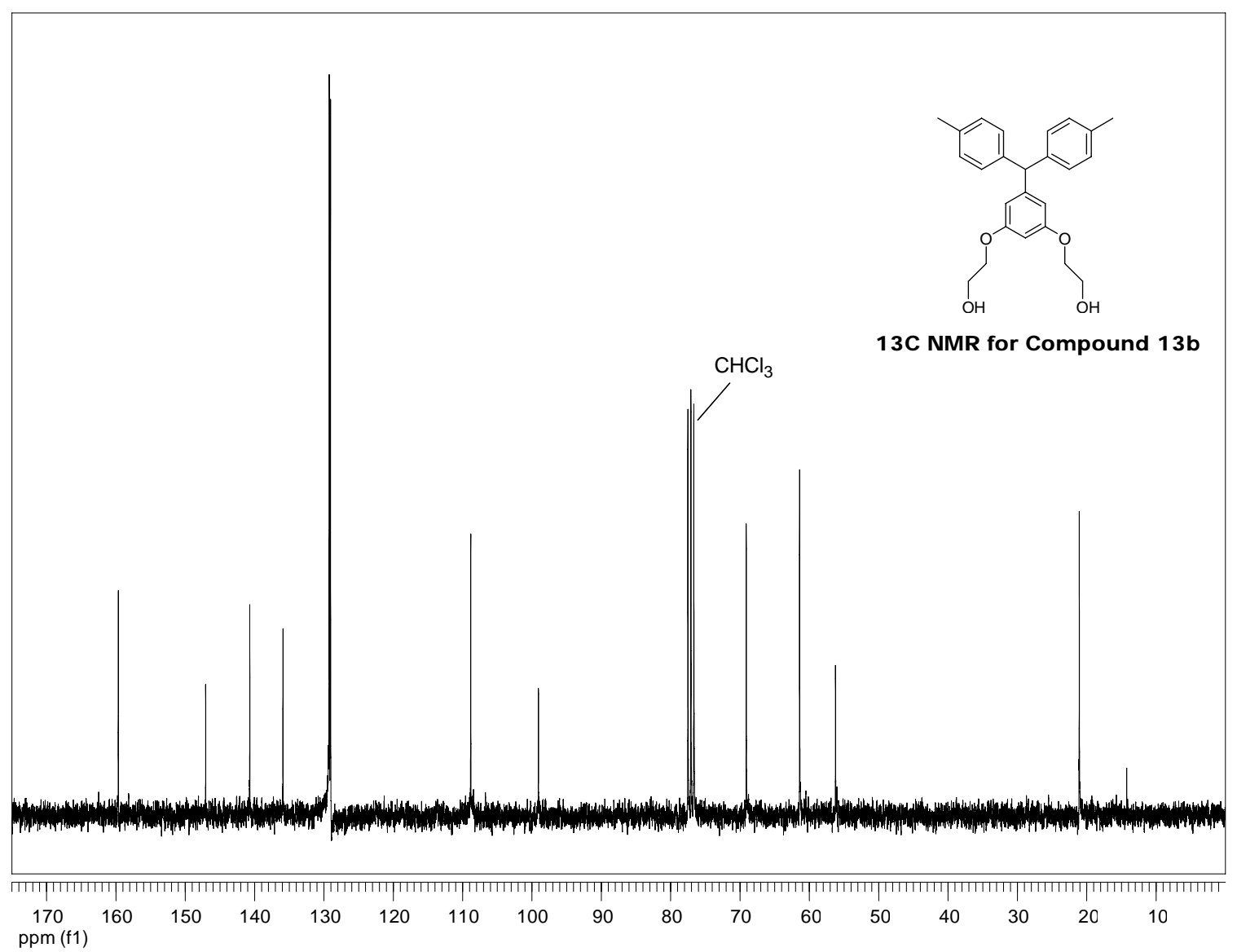

1,3-Bis-(2-bromo-ethoxy)-5-di-p-tolylmethyl-benzene (14b). To a suspension of triphenylphosphine $(5.84 \mathrm{~g}, 22.3 \mathrm{mmol})$ in acetonitrile $(25 \mathrm{ml})$ was added bromine $(3.56$ $\mathrm{g}, 22.3 \mathrm{mmol})$ in acetonitrile $(20 \mathrm{ml})$ at $-10^{\circ}$ over $1 \mathrm{~h}$. The mixture was allowed to warm to room temperature and 2-[3-di-p-tolylmethyl-5-(2-hydroxy-ethoxy)-phenoxy]-ethanol (13b) $(3.8 \mathrm{~g}, 9.68 \mathrm{mmol})$ in acetonitrile $(10 \mathrm{ml})$ were added. The reaction mixture was stirred at room temperature for $24 \mathrm{~h}$. Acetonitrile was removed in vacuo and the residue was purified by flash chromatography with methylene chloride to give a brown paste (2.8g, 56\%). ${ }^{1} \mathbf{H}$ NMR $\left(\mathrm{CDCl}_{3}, 300 \mathrm{MHz}\right): \delta 7.18(\mathrm{~d}, \mathrm{~J}=7.9 \mathrm{~Hz}, 4 \mathrm{H}), 7.09$ (d, J=8.2 Hz, 4H), $6.42(\mathrm{t}, \mathrm{J}=2.6 \mathrm{~Hz}, 1 \mathrm{H}), 6.41(\mathrm{~d}, \mathrm{~J}=2.1 \mathrm{~Hz}, 2 \mathrm{H}), 5.48(\mathrm{~s}, 1 \mathrm{H}), 4.25(\mathrm{t}, \mathrm{J}=6.2 \mathrm{~Hz}, 4 \mathrm{H})$, $3.63(\mathrm{t}, \mathrm{J}=6.2 \mathrm{~Hz}, 4 \mathrm{H}), 2.41(\mathrm{~s}, 6 \mathrm{H}) .{ }^{13} \mathrm{C} \mathbf{N M R}\left(\mathrm{CDCl}_{3}, 75 \mathrm{MHz}\right): \delta 159.2,147.3,140.7$, 
136.0, 129.3, 129.2, 109.2, 99.6, 67.8, 56.3, 29.2, 21.2 MS (ESI): m/z $539.1\left(\mathrm{M}^{+},+\mathrm{Na}\right)$ $\left(\mathrm{C}_{25} \mathrm{H}_{26} \mathrm{Br}_{2} \mathrm{O}_{2}\right.$ requires 516.03).

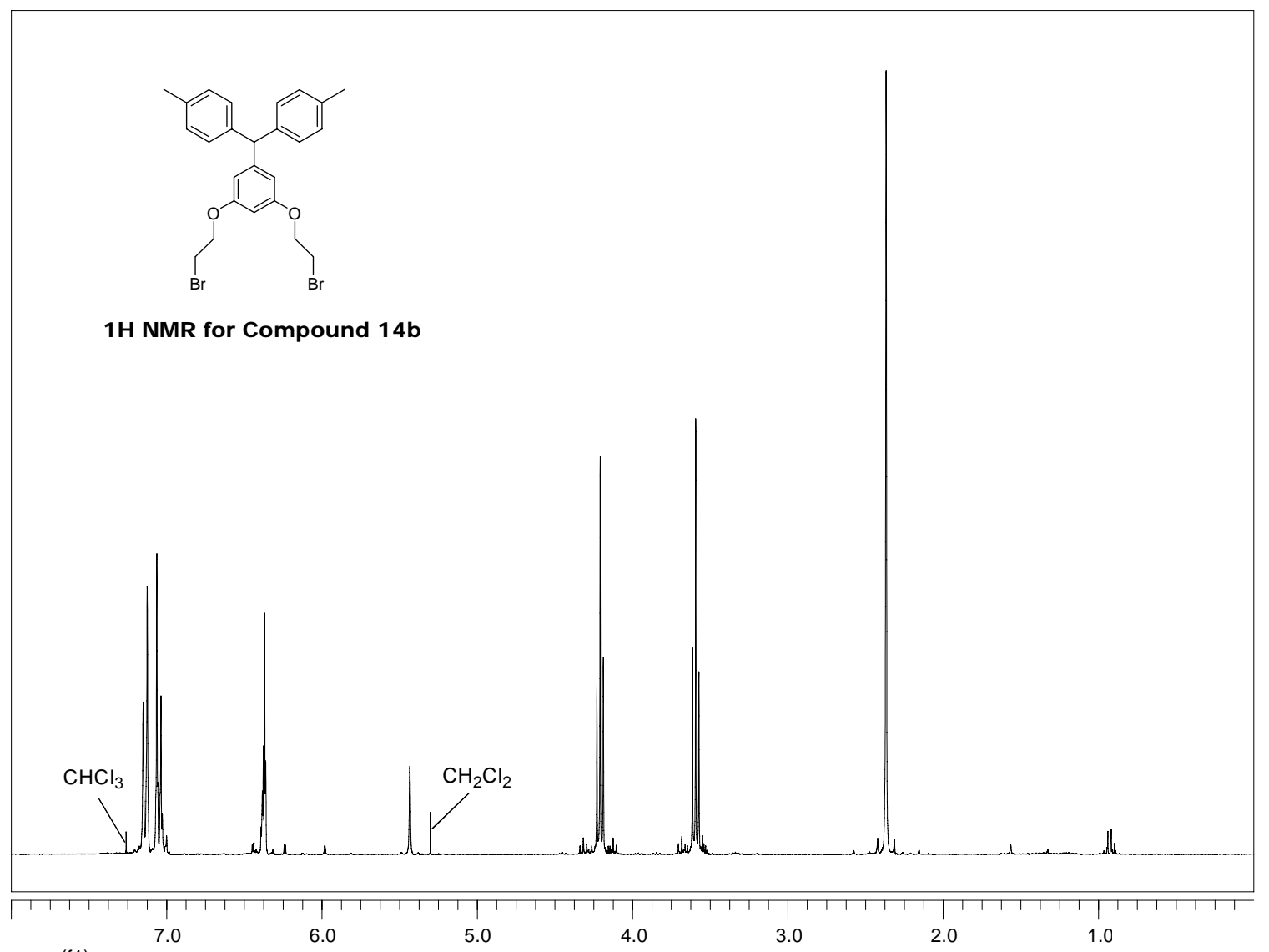

ppm (f1) 


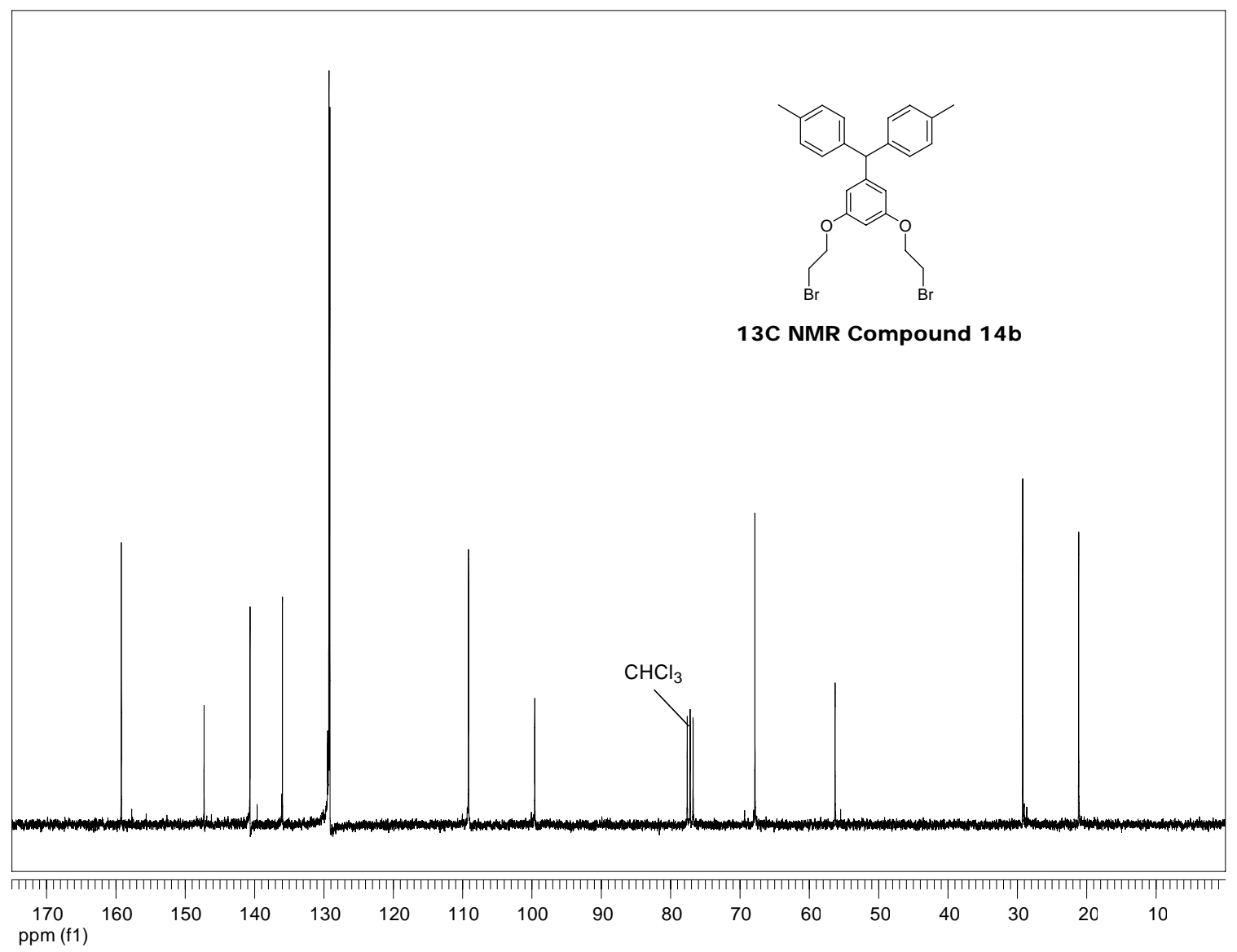

\section{1,3-Bis-(2-(4,4'-dipyridinium)-ethoxy)-5-di-p-tolylmethyl-benzene}

dihexafluorophosphate (15b). A mixture of 1,3-bis-(2-bromo-ethoxy)-5-di-p-

tolylmethyl-benzene (14b) (1.2 g, $2.31 \mathrm{mmol})$ and 4,4'-dipyridyl (1.8 g, $11.6 \mathrm{mmol})$ was

stirred at $65^{\circ} \mathrm{C}$ for 2 days. The mixture was allowed to cool and concentrated in vacuo.

The residue was dissolved in hot water and ammonium hexafluorophosphate $(0.75 \mathrm{~g}$, $4.62 \mathrm{mmol}$ ) was added to the aqueous solution. Brown oil precipitated to the bottom of the flask and the aqueous layer was decanted. The oil was washed with chloroform $(6 \times 10$ $\mathrm{ml})$ to give a brown solid $(1.9 \mathrm{~g}, 86 \%) .{ }^{1} \mathbf{H}$ NMR $\left(\mathrm{C}_{3} \mathrm{D}_{6} \mathrm{O}, 300 \mathrm{MHz}\right): \delta 9.25(\mathrm{~d}, \mathrm{~J}=7.0$ Hz, 4H), 8.86 (d, J=5.9 Hz, 4H), 8.61 (d, J=6.7, 4H), 7.95 (d, J=6.1 Hz, 4H), 7.07 (d, $\mathrm{J}=7.9 \mathrm{~Hz}, 4 \mathrm{H}), 6.97(\mathrm{~d}, \mathrm{~J}=8.2 \mathrm{~Hz}, 4 \mathrm{H}), 6.57(\mathrm{t}, \mathrm{J}=2.1,1 \mathrm{H}), 6.40(\mathrm{~d}, \mathrm{~J}=2.1 \mathrm{~Hz}, 2 \mathrm{H}), 5.40$ 
(s, 1H), $5.24(\mathrm{t}, \mathrm{J}=4.7 \mathrm{~Hz}, 4 \mathrm{H}), 4.59(\mathrm{t}, \mathrm{J}=4.7 \mathrm{~Hz}, 4 \mathrm{H}), 2.25(\mathrm{~s}, 6 \mathrm{H}) .{ }^{13} \mathrm{C} \mathbf{N M R}\left(\mathrm{C}_{3} \mathrm{D}_{6} \mathrm{O}\right.$, 75MHz): $\delta 159.9,155.4,152.2,148.4,147.1,142.1,141.6,136.7,130.0,129.8,126.7$, 122.7, 110.1, 100.6, 79.3, 67.3, 61.6, 56.8, 21.0. MS (ESI): $\mathrm{m} / \mathrm{z} 335.2\left(\mathrm{M}^{2+}\right), 815.4\left(\mathrm{M}^{+}\right.$, $\left.+\mathrm{PF}_{6}^{-}\right)\left(\mathrm{C}_{45} \mathrm{H}_{42} \mathrm{~N}_{4} \mathrm{O}_{2}{ }^{2+}\right.$ requires 670.33).

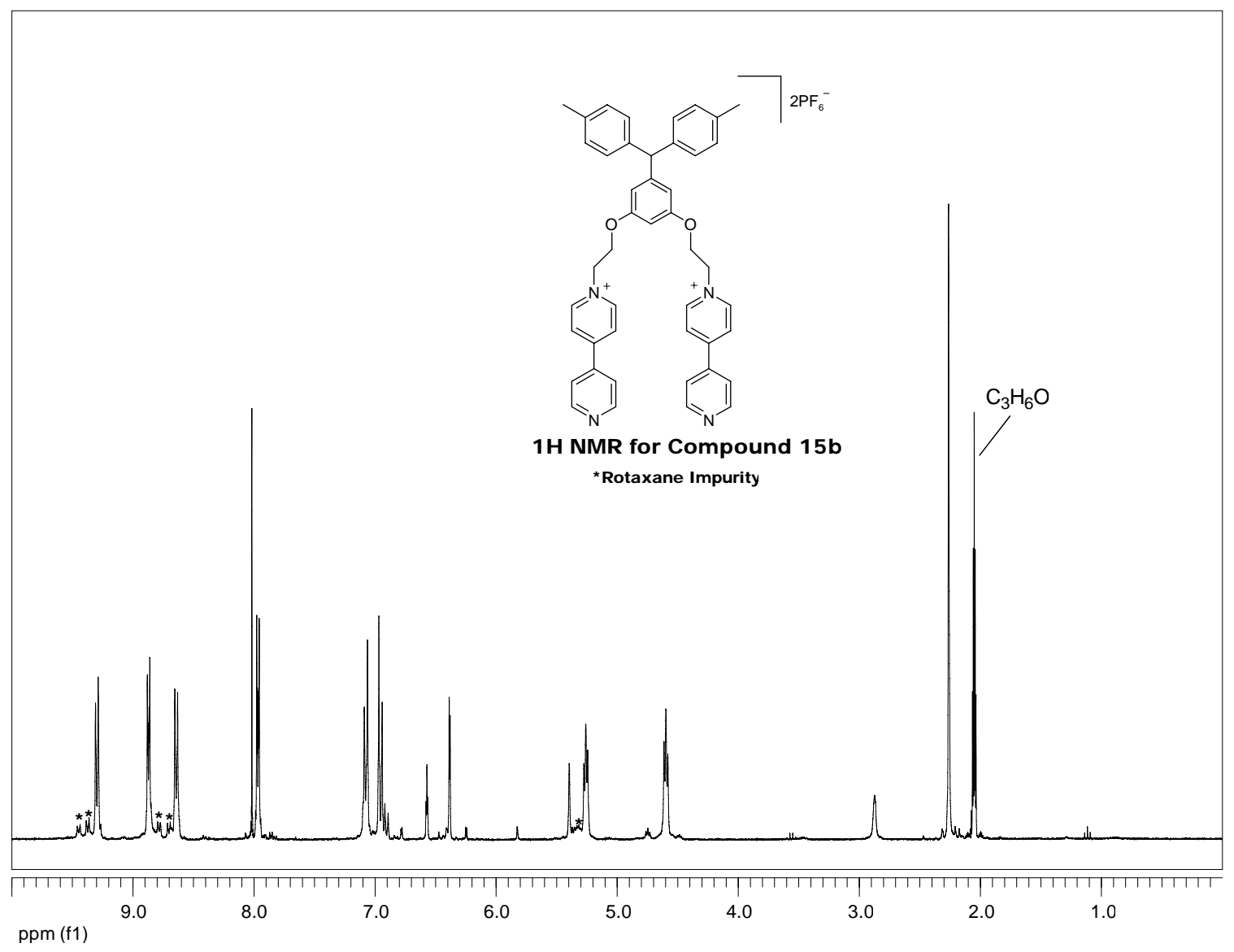




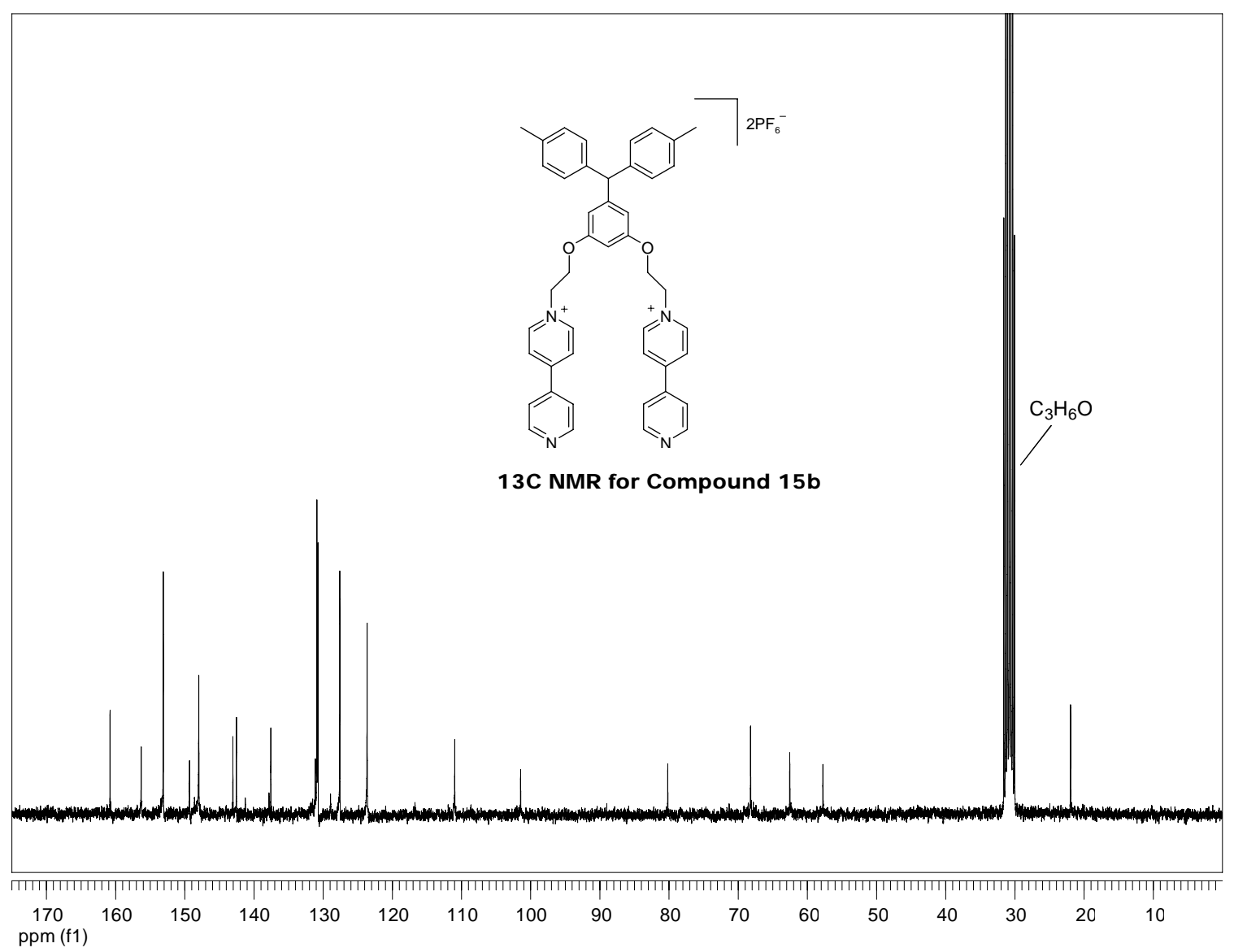

Purification of Catenanes. After stirring for 3 to 4 days the catenane solutions were purified and isolated according to the following method. The dark red solid was dissolved in approximately $10 \mathrm{ml}$ of $\mathrm{CH}_{3} \mathrm{OH} / \mathrm{EtOAc} / \mathrm{CH}_{3} \mathrm{COCH}_{3}(1: 1: 1)$ and loaded onto a $2 \mathrm{~mm}$ preparative TLC plate. After drying, the plate was eluted twice with $\mathrm{CH}_{3} \mathrm{OH} /$ EtOAc $(1: 1)$ at $35^{\circ} \mathrm{C}\left(\mathrm{R}_{f}=0.1\right)$ and finally with $\mathrm{CH}_{3} \mathrm{OH} / 2 \mathrm{M} \mathrm{NH}{ }_{4} \mathrm{Cl} / \mathrm{CH}_{3} \mathrm{NO}_{2}$ (7:2:1) at room temperature $\left(\mathrm{R}_{f}=0.3-0.4\right)$. The product was washed from the silica gel using the final eluant and $\mathrm{NH}_{4} \mathrm{PF}_{6}(0.300 \mathrm{~g})$ was added to the red solution. Solvents $\mathrm{CH}_{3} \mathrm{OH}$ and $\mathrm{CH}_{3} \mathrm{NO}_{2}$ were removed via rotary evaporator leaving a red solid suspended in water. This red product was filtered, washed with distilled water, and allowed to dry. 
Impurities detected after the first separation were removed by an additional purification using a $0.5 \mathrm{~mm}$ PLC plate and identical procedures.

Catenane 1. 1,3-Di(2-(4,4'-dipyridinium)ethoxy)benzene (15a) $(0.123 \mathrm{~g}, 0.16 \mathrm{mmol})$ and $\mathrm{BPP} 34 \mathrm{C} 10$ (0.223 g, $0.416 \mathrm{mmol})$ were combined and dissolved in $\mathrm{CH}_{3} \mathrm{CN}(15 \mathrm{ml})$. This solution was allowed to stir for 10 minutes at which point $\alpha, \alpha$ '-dibromo- $m$-xylene $(0.051 \mathrm{~g}, 0.192 \mathrm{mmol})$ was added and the reaction vessel sealed with a septa. This red solution stirred 4 days under ambient conditions after which time the solvent was removed in vacuo. The catenane was purified and after removal of solvent in vacuo, 74 $\mathrm{mg}(27 \%)$ of red solid was recovered. ${ }^{1} \mathbf{H}$ NMR $\left(\mathrm{C}_{3} \mathrm{D}_{6} \mathrm{O}, 400 \mathrm{MHz}\right): \delta \mathrm{ppm} 9.38(\mathrm{~d}$, $J=6.8 \mathrm{~Hz}, 4 \mathrm{H}), 9.20(\mathrm{~d}, J=6.8 \mathrm{~Hz}, 4 \mathrm{H}), 8.19-8.12(\mathrm{~m}, 12 \mathrm{H}), 7.28(\mathrm{t}, J=8.4 \mathrm{~Hz}, 1 \mathrm{H}), 6.73$ (t, $J=2.3 \mathrm{~Hz}, 1 \mathrm{H}), 6.67$ (dd, $J=8.4,2.3 \mathrm{~Hz}, 2 \mathrm{H}), 6.10$ (bs, 4H), 5.28 (t, $J=4.4 \mathrm{~Hz}, 4 \mathrm{H})$, $4.63(\mathrm{t}, J=4.4 \mathrm{~Hz}, 4 \mathrm{H}), 3.90-3.80(\mathrm{~m}, 14 \mathrm{H}), 3.76(\mathrm{~m}, 10 \mathrm{H}), 3.61-3.50(\mathrm{~m}, 10 \mathrm{H}), 2.89$ (bs, $2 \mathrm{H}) 2.86(\mathrm{bs}, 2 \mathrm{H}) .{ }^{13} \mathrm{C}$ NMR $\left(\mathrm{C}_{3} \mathrm{D}_{6} \mathrm{O}, 75 \mathrm{MHz}\right): \delta 160.7,153.6,148.2,147.9,147.5$, 147.2, 136.1, 135.7, 133.9, 132.9, 132.2, 127.7, 127.3, 116.4, 108.0, 106.8, 72.1, 72.0, 71.6, 69.2, 68.0, 66.2, $62.7 \mathrm{MS}(\mathrm{ESI}): 703.4\left(\mathrm{M}^{2+},+\mathrm{PF}_{6}{ }^{-}\right), 630.9\left(\mathrm{M}^{2+},+\mathrm{PF}_{6}\right), 420.6$ $\left(\mathrm{M}^{4+},+\mathrm{PF}_{6}{ }^{-}\right) 372.2\left(\mathrm{M}^{3+}\right), 279.2\left(\mathrm{M}^{4+}\right)\left(\mathrm{C}_{66} \mathrm{H}_{76} \mathrm{~N}_{4} \mathrm{O}_{12}{ }^{4+}\right.$ requires 1117.33). 
Supporting Information

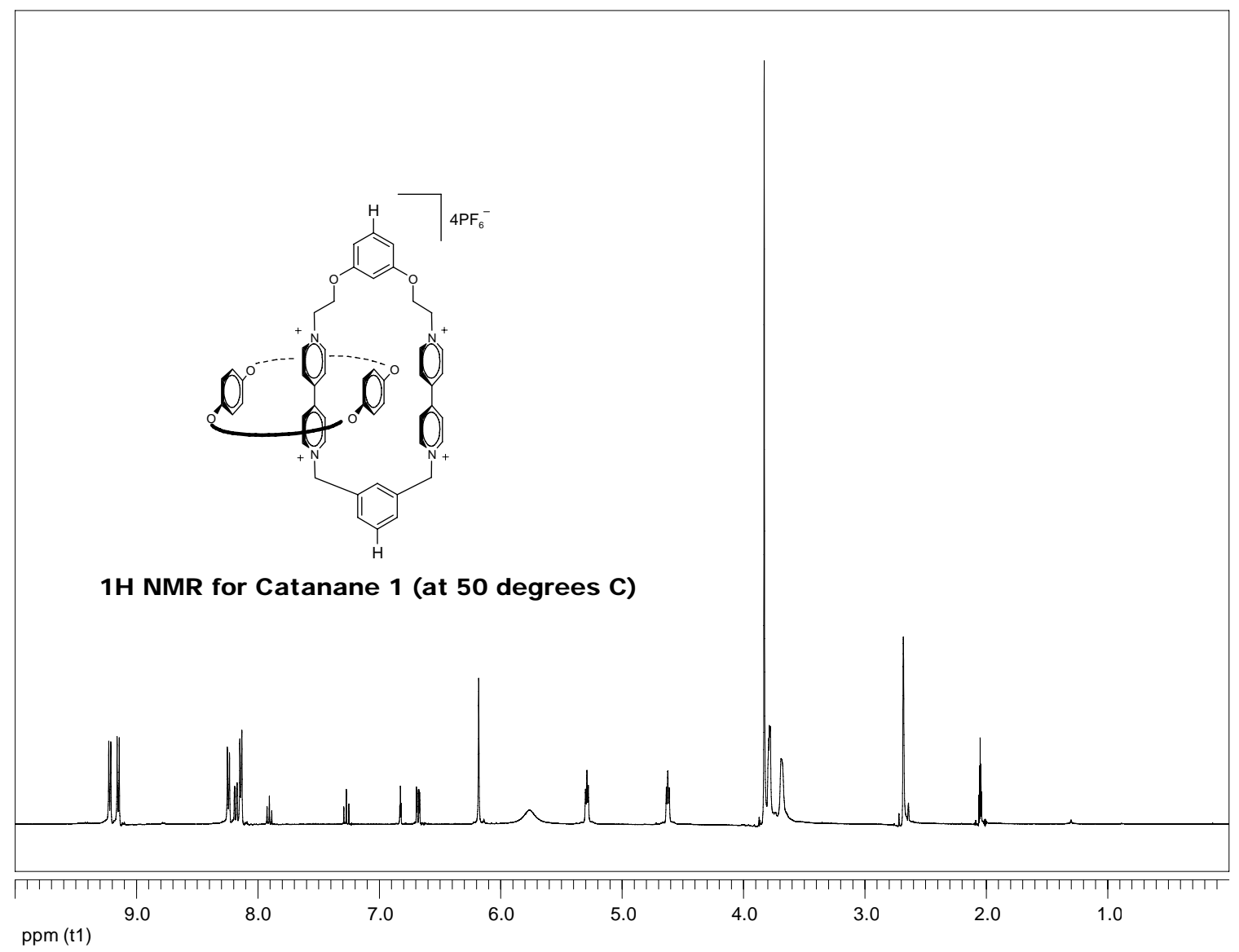




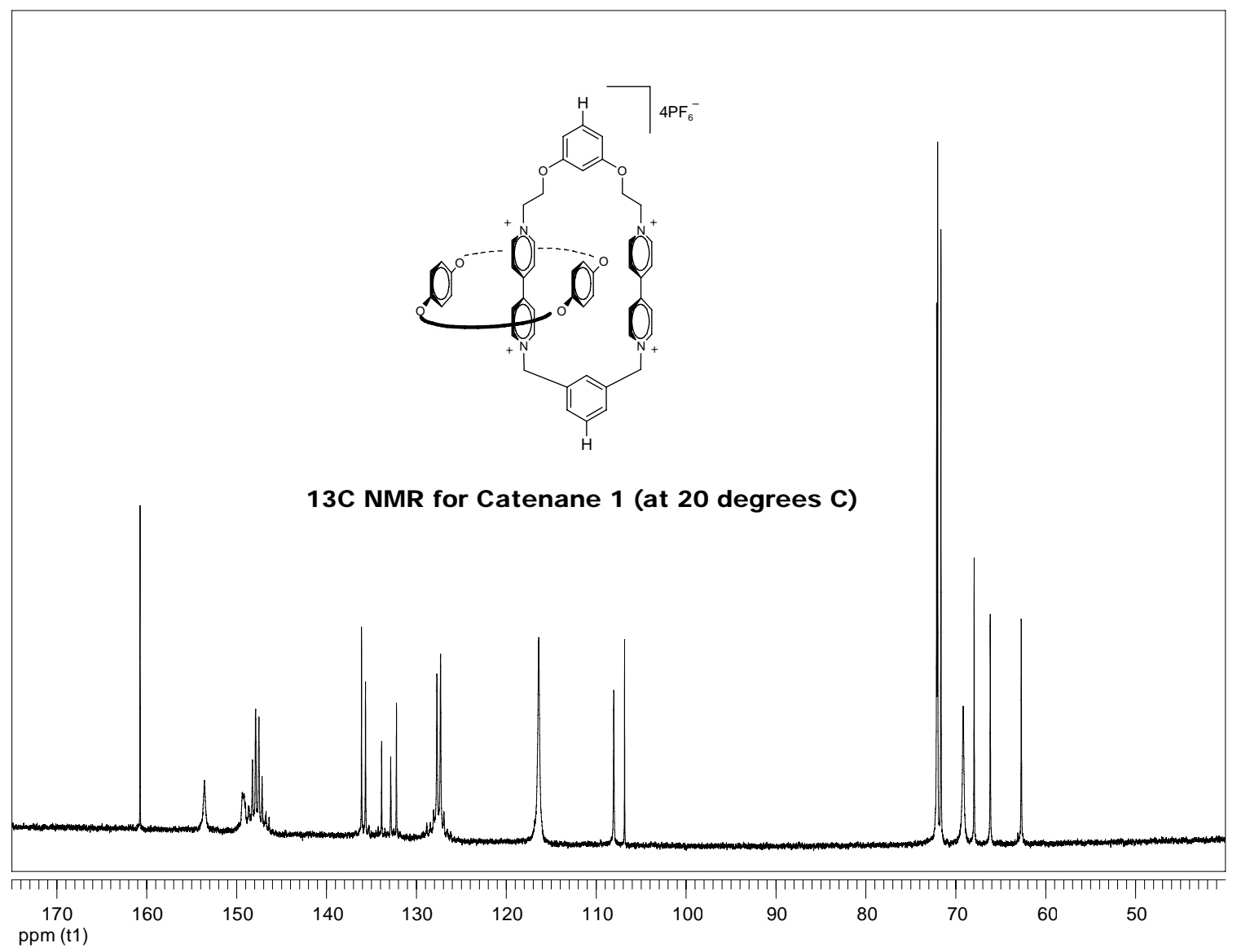

Catenane 2. 1,3-Di(2-(4,4'-dipyridinium)ethoxy)benzene (15a) $(0.123 \mathrm{~g}, 0.16 \mathrm{mmol})$ and $\mathrm{BPP} 34 \mathrm{C} 10(0.223 \mathrm{~g}, 0.416 \mathrm{mmol})$ were combined and dissolved in $\mathrm{CH}_{3} \mathrm{CN}(15 \mathrm{ml})$. This solution was allowed to stir for 10 minutes at which point 5-bis(bromomethyl)-4'(1,1'-dimethylethyl)-1,1'-biphenyl (0.0765 g, $0.192 \mathrm{mmol})$ was added and the reaction vessel sealed with a septa. This red solution stirred 4 days under ambient conditions after which time the solvent was removed in vacuo. The catenane was purified and after drying, $72 \mathrm{mg}$ (23\%) of red solid was recovered. ${ }^{1} \mathbf{H}$ NMR $\left(\mathrm{C}_{3} \mathrm{D}_{6} \mathrm{O}, 400 \mathrm{MHz}\right): \delta 9.25$ (d, J=7.0 Hz, 4H), $8.86(d, J=5.9 \mathrm{~Hz}, 4 \mathrm{H}), 8.61(\mathrm{~d}, \mathrm{~J}=6.7,4 \mathrm{H}), 7.95(\mathrm{~d}, \mathrm{~J}=6.1 \mathrm{~Hz}, 4 \mathrm{H})$, 7.07 (d, J=7.9 Hz, 4H), 6.97 (d, J=8.2 Hz, 4H), 6.57 (t, J=2.1, 1H), 6.40 (d, J=2.1 Hz, 2H), $5.40(\mathrm{~s}, 1 \mathrm{H}), 5.24(\mathrm{t}, \mathrm{J}=4.7 \mathrm{~Hz}, 4 \mathrm{H}), 4.59(\mathrm{t}, \mathrm{J}=4.7 \mathrm{~Hz}, 4 \mathrm{H}), 2.25(\mathrm{~s}, 6 \mathrm{H}) .{ }^{13} \mathrm{C}$ NMR 
$\left(\mathrm{C}_{3} \mathrm{D}_{6} \mathrm{O}, 75 \mathrm{MHz}\right): \delta 160.7,153.5,147.8,147.6,145.1,137.6,136.7,133.5,132.2,132.0$ $128.9,127.9,127.7,127.3,116.3,108.0,106.7,72.0,71.9,71.6,69.1,67.9,66.2,62.6$, 36.2, 32.5, 2.0. MS (ESI): $769.4\left(\mathrm{M}^{2+},+\mathrm{PF}_{6}{ }^{-}\right), 696.9\left(\mathrm{M}^{4+},+\mathrm{PF}_{6}{ }^{-}\right), 464.6\left(\mathrm{M}^{3+},+\mathrm{PF}_{6}{ }^{-}\right)$, $416.3\left(\mathrm{M}^{3+}\right), 312.2\left(\mathrm{M}^{4+}\right)\left(\mathrm{C}_{76} \mathrm{H}_{88} \mathrm{~N}_{4} \mathrm{O}_{12}{ }^{4+}\right.$ requires 1249.53)

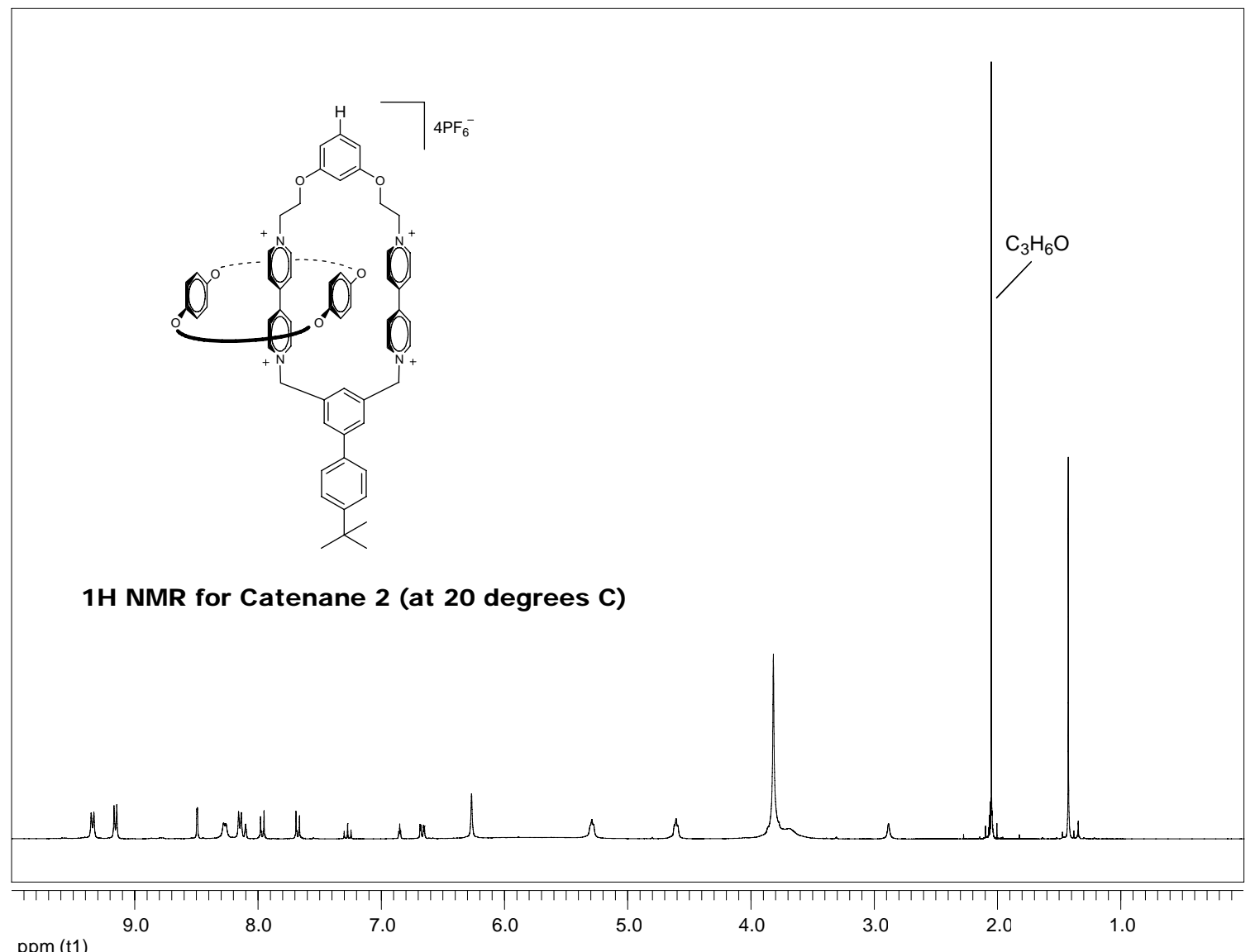

ppm (t1) 


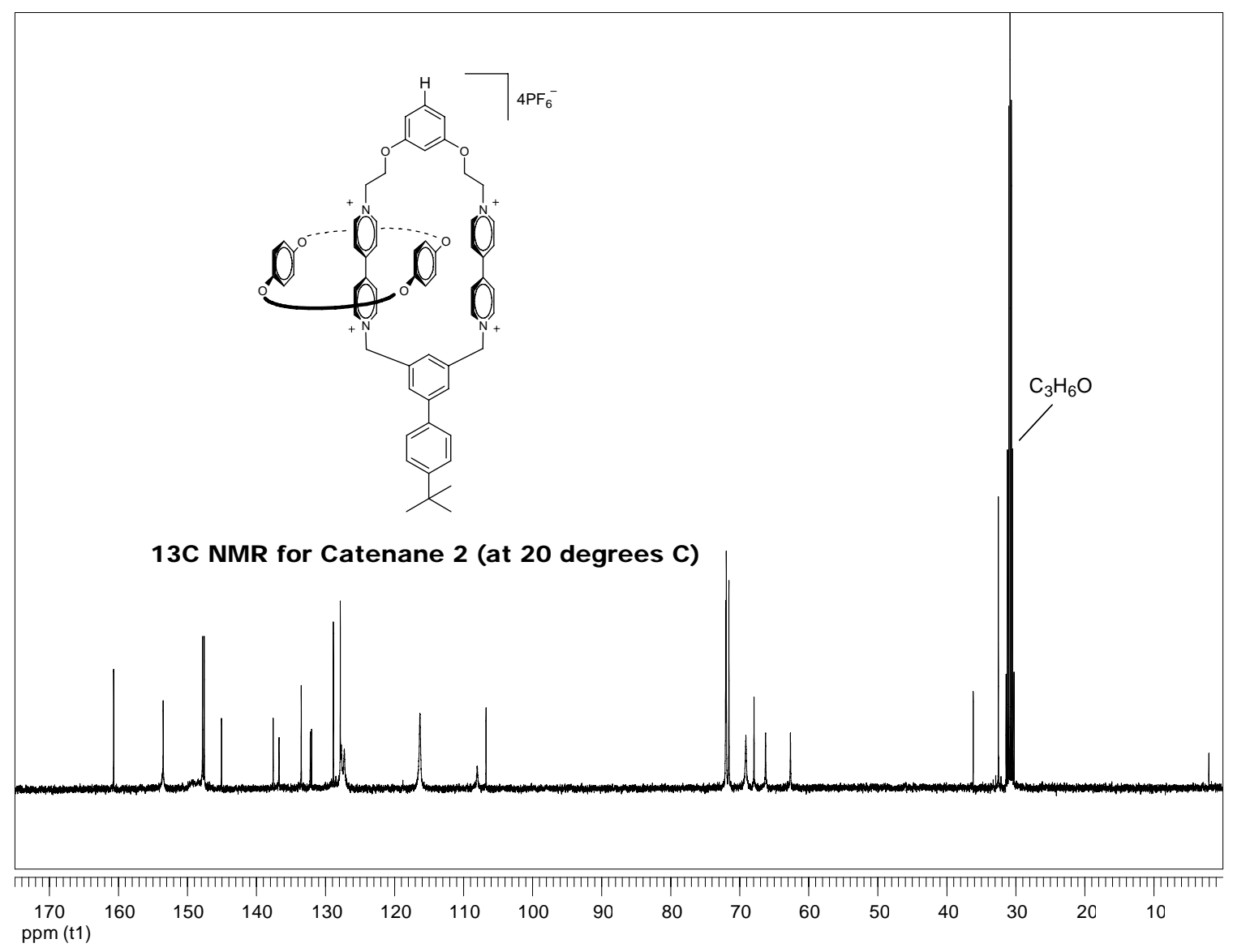

Catenane 3. 1,3-Bis-(2-(4,4'-dipyridinium)-ethoxy)-5-di-p-tolylmethyl-benzene dihexafluorophosphate (15b) $(0.140 \mathrm{~g}, 0.146 \mathrm{mmol})$ and BPP34C10 (0.125 g, 0.233 mmol) were combined and dissolved in $\mathrm{CH}_{3} \mathrm{CN}(15 \mathrm{ml})$. This solution was allowed to stir for 10 minutes at which point $\alpha, \alpha$ '-dibromo-m-xylene $(0.050 \mathrm{~g}, 0.190 \mathrm{mmol})$ was added and the reaction vessel sealed with a septa. This red solution stirred 4 days under ambient conditions after which time the solvent was removed in vacuo. The catenane was purified and after drying, $21 \mathrm{mg}(7 \%)$ of red solid was recovered. ${ }^{1} \mathbf{H}$ NMR $\left(\mathrm{C}_{3} \mathrm{D}_{6} \mathrm{O}\right.$, $400 \mathrm{MHz}): \delta 9.24$ (d, J=6.8 Hz, 4H), $9.13(\mathrm{~d}, \mathrm{~J}=6.8 \mathrm{~Hz}, 4 \mathrm{H}), 8.26 \sim 8.13(\mathrm{~m}, 12 \mathrm{H}), 7.15$ (d, $\mathrm{J}=8.0 \mathrm{~Hz}, 4 \mathrm{H}), 7.05(\mathrm{~d}, \mathrm{~J}=8.2 \mathrm{~Hz}, 4 \mathrm{H}), 6.71(\mathrm{t}, \mathrm{J}=2.1 \mathrm{~Hz}, 1 \mathrm{H}), 6.50(\mathrm{~d}, \mathrm{~J}=2.1 \mathrm{~Hz}, 2 \mathrm{H})$, $6.20(\mathrm{~s}, 4 \mathrm{H}), 5.49(\mathrm{~s}, 1 \mathrm{H}), 5.25(\mathrm{t}, \mathrm{J}=4.5 \mathrm{~Hz}, 4 \mathrm{H}), 4.50(\mathrm{t}, \mathrm{J}=4.5 \mathrm{~Hz}, 4 \mathrm{H}), 3.80(\mathrm{br}, 32 \mathrm{H})$, 
$2.31(\mathrm{~s}, 6 \mathrm{H}) .{ }^{13} \mathrm{C}$ NMR $\left(\mathrm{C}_{3} \mathrm{D}_{6} \mathrm{O}, 75 \mathrm{MHz}\right): \delta 158.7,151.8,147.5,146.7,146.1,145.7$, $140.8,135.7,134.2,133.8,132.1,131.0,129.1,129.0,127.6,127.1,125.9,125.5,114.6$, 107.4, 103.3, 70.3, 70.2, 69.8, 67.3, 66.1, 64.3, 60.8, 56.3, 20.1. MS (ESI): m/z 327.9 $\left(\mathrm{M}^{4+}\right), 485.6\left(\mathrm{M}^{3+},+\mathrm{PF}_{6}{ }^{-}\right), 801.0\left(\mathrm{M}^{2+},+\mathrm{PF}_{6}^{-}\right)\left(\mathrm{C}_{81} \mathrm{H}_{90} \mathrm{~N}_{4} \mathrm{O}_{12}{ }^{4+}\right.$ requires 1361.65).

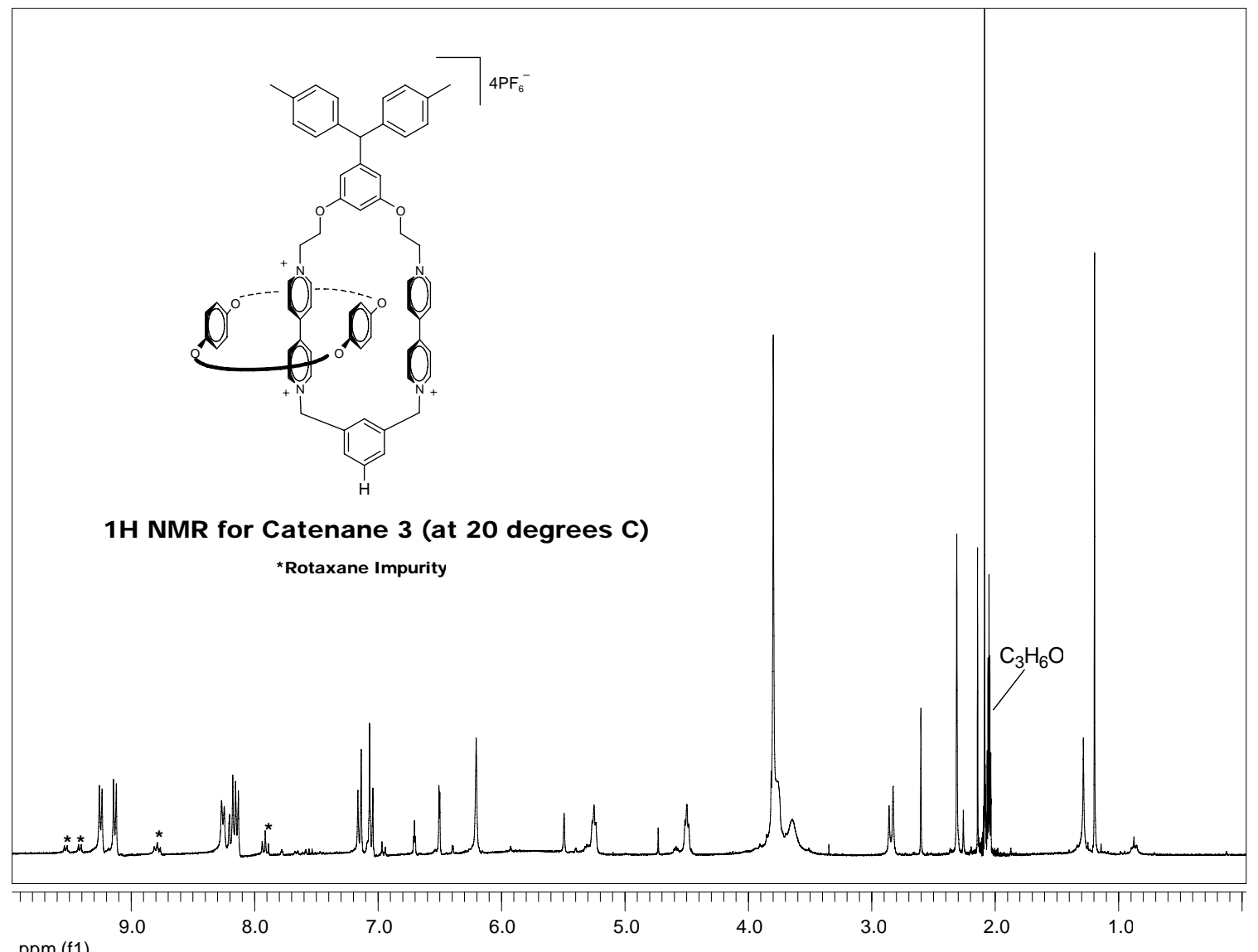

ppm (f1)

Catenane 4. 1,3-Bis-(2-(4,4'-dipyridinium)-ethoxy)-5-di-p-tolylmethyl-benzene dihexafluorophosphate (15b) $(0.140 \mathrm{~g}, 0.146 \mathrm{mmol})$ and BPP34C10 (0.125 g, 0.233 mmol) were combined and dissolved in $\mathrm{CH}_{3} \mathrm{CN}(15 \mathrm{ml})$. This solution was allowed to stir for 10 minutes at which point 5-bis(bromomethyl)-4'-(1,1'-dimethylethyl)-1,1'biphenyl $(0.050 \mathrm{~g}, 0.190 \mathrm{mmol})$ was added and the reaction vessel sealed with a septa. This red solution stirred 4 days under ambient conditions after which time the solvent 
was removed in vacuo. The catenane was then purified. The catenane was purified and after drying a red solid was recovered. ${ }^{1} \mathbf{H}$ NMR $\left(\mathrm{C}_{3} \mathrm{D}_{6} \mathrm{O}, 400 \mathrm{MHz}\right): \delta 9.44(\mathrm{~d}, \mathrm{~J}=6.8 \mathrm{~Hz}$, 2H), 9.35 (d, J=7.0 Hz, 2H), 9.15 (d, J=6.8 Hz, 2H), 9.10 (d, J=7.0 Hz), 8.48 (d, J=10.0 $\mathrm{Hz}, 2 \mathrm{H}), 8.39(\mathrm{~d}, \mathrm{~J}=6.5,2 \mathrm{H}), 8.23 \sim 8.10(\mathrm{~m}, 7 \mathrm{H}), 7.96(\mathrm{~d}, \mathrm{~J}=8.5 \mathrm{~Hz}, 2 \mathrm{H}), 7.66(\mathrm{~d}, \mathrm{~J}=8.8$ Hz, 2H), 7.15 (d, J=7.9 Hz, 4H), $7.06(\mathrm{~d}, \mathrm{~J}=8.2 \mathrm{~Hz}, 4 \mathrm{H}), 6.68$ (t, J=2.1 Hz, 1H), 6.52 (d, $\mathrm{J}=2.1 \mathrm{~Hz}, 2 \mathrm{H}), 6.33(\mathrm{~s}, 2 \mathrm{H}), 6.25(\mathrm{~s}, 2 \mathrm{H}), 5.80(\mathrm{~s}$, broad, 7H), $5.49(\mathrm{~s}, 1 \mathrm{H}), 5.26(\mathrm{t}, \mathrm{J}=4.7$ $\mathrm{Hz}, 2 \mathrm{H}), 5.21(\mathrm{t}, \mathrm{J}=4.7 \mathrm{~Hz}, 2 \mathrm{H}), 4.55(\mathrm{t}, \mathrm{J}=4.7 \mathrm{~Hz}, 2 \mathrm{H}), 4.48(\mathrm{t}, \mathrm{J}=4.7 \mathrm{~Hz}, 2 \mathrm{H}), 3.83 \sim 3.67$ (m, 32H), $2.31(\mathrm{~s}, 6 \mathrm{H}), 1.42(\mathrm{~s}, 9 \mathrm{H}) .{ }^{13} \mathbf{C}$ NMR $\left(\mathrm{C}_{3} \mathrm{D}_{6} \mathrm{O}, 75 \mathrm{MHz}\right): \delta$ 158.9, 158.6, 151.7, $148.7,148.5,147.5,146.3,146.1,146.0,143.2,140.8,135.9,135.8,135.27,134.8,131.8$, $131.7,130.4,129.1,129.3,127.1,126.6,126.2,126.1,126.0,125.4,125.0,114.6,108.2$, 107.1, 103.2, 70.4, 70.2, 69.9, 67.4, 66.4, 66.0, 64.6, 64.2, 61.0, 60.6, 56.3, 34.4, 30.8, 21.2. 
Supporting Information

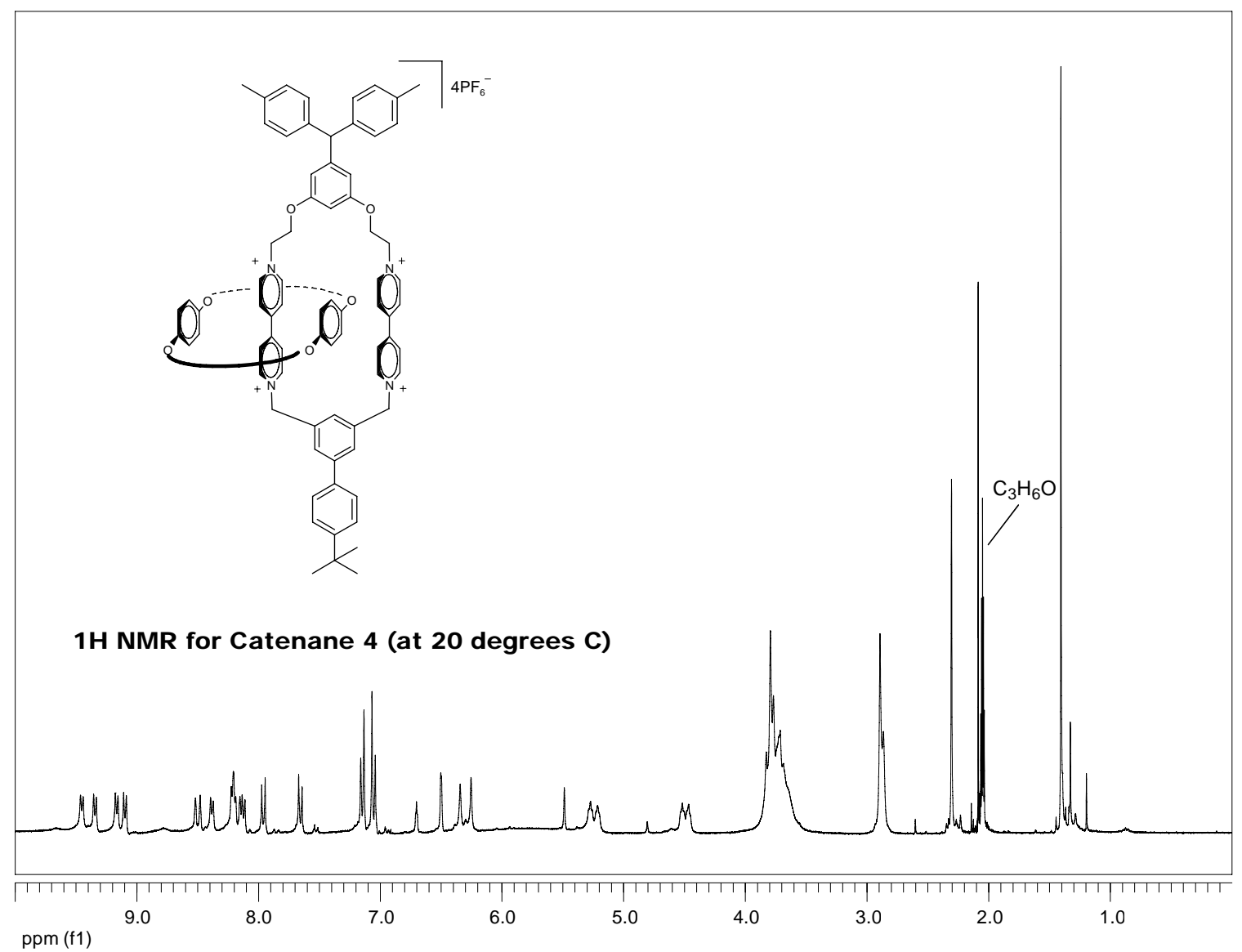




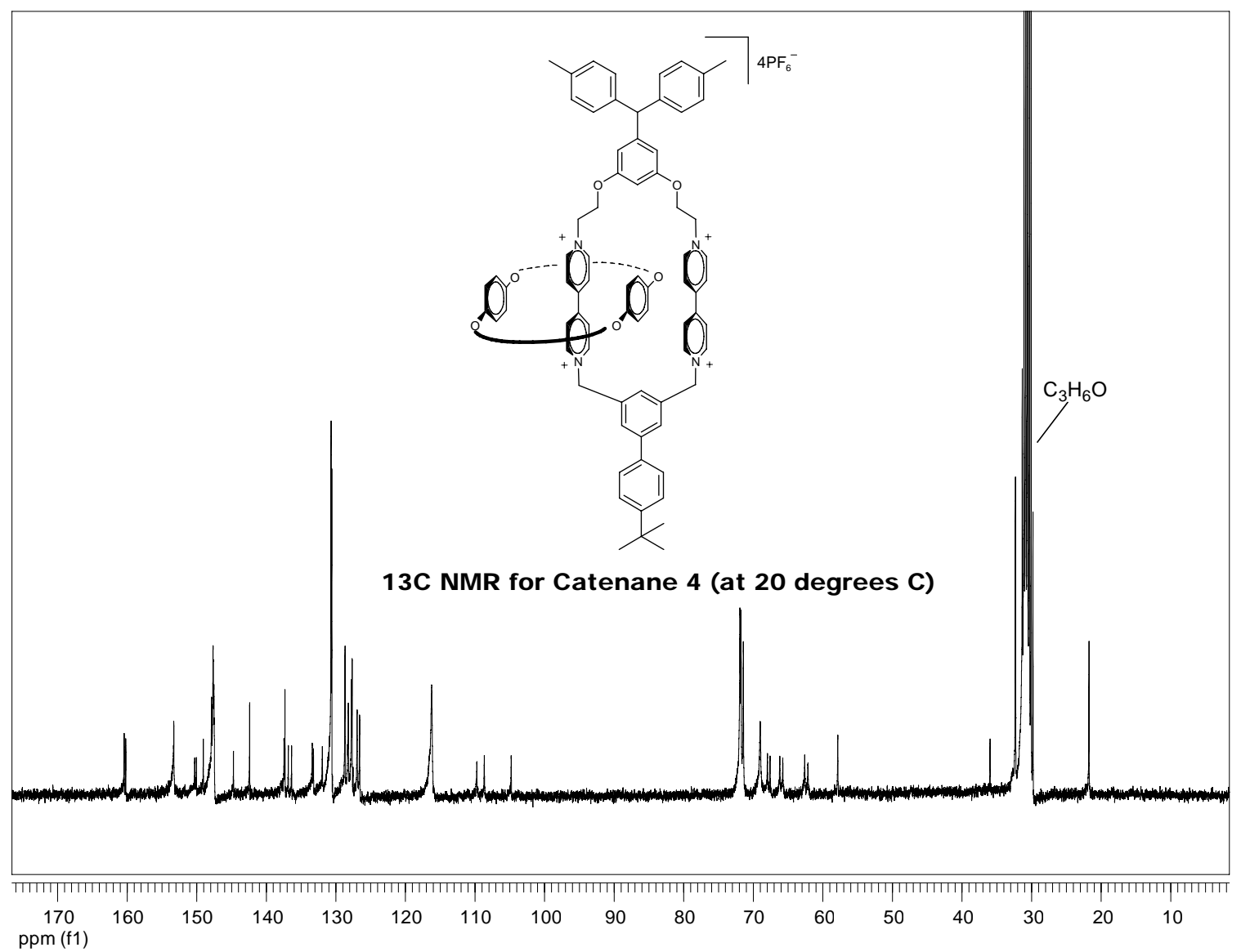

Catenane 5. 1,3-Di(2-(4,4'-dipyridinium)ethoxy)benzene (15a) (0.123 g, 0.16 mmol) and $\mathrm{BPP} 34 \mathrm{C} 10$ (0.223 $\mathrm{g}, 0.416 \mathrm{mmol})$ were dissolved in $\mathrm{CH}_{3} \mathrm{CN}$ (15 ml). This solution was allowed to stir for 10 minutes at which point $\alpha, \alpha^{\prime}$-dibromo- $p$-xylene $(0.051 \mathrm{~g}, 0.192$ mmol) was added and the reaction vessel sealed with a septa. This red solution stirred 4 days under ambient conditions after which time the solvent was removed in vacuo. The catenane was purified and after drying $91 \mathrm{mg}$ (32\%) of red solid was recovered. ${ }^{1} \mathbf{H}$ $\operatorname{NMR}\left(\mathrm{C}_{3} \mathrm{D}_{6} \mathrm{O}, 400 \mathrm{MHz}\right): \delta 9.22(\mathrm{~d}, J=7.0 \mathrm{~Hz}, 4 \mathrm{H}), 9.15(\mathrm{~d} J=7.0 \mathrm{~Hz}, 4 \mathrm{H}), 8.24$ (d, $J=7.0 \mathrm{~Hz}, 4 \mathrm{H}), 8.20-8.12(\mathrm{~m}, 7 \mathrm{H}), 7.91(\mathrm{t}, J=7.7 \mathrm{~Hz}, 1 \mathrm{H}), 7.27(\mathrm{t}, J=8.4 \mathrm{~Hz}, 1 \mathrm{H}), 6.83(\mathrm{t}$, $J=2.4 \mathrm{~Hz}, 1 \mathrm{H}), 6.68(\mathrm{dd}, J=8.4,2.4 \mathrm{~Hz}, 2 \mathrm{H}), 6.18(\mathrm{~s}, 4 \mathrm{H}), 5.76(\mathrm{bs}, 6 \mathrm{H}), 5.29(\mathrm{t}, J=4.4$ $\mathrm{Hz}, 4 \mathrm{H}), 4.62$ (t, J=4.8 Hz, 4H), $3.83(\mathrm{bs}, 16 \mathrm{H}), 3.81-3.76(\mathrm{~m}, 10 \mathrm{H}), 3.69(\mathrm{bs}, 8 \mathrm{H}) .{ }^{13} \mathrm{C}$ 
NMR $\left(\mathrm{C}_{3} \mathrm{D}_{6} \mathrm{O}, 75 \mathrm{MHz}\right): \delta 146.0,144.9,130.9,130.3,125.8,105.8,104.5,70.1,70.0$ 69.7, 67.2, 65.7, 64.7, 60.6 MS (ESI): $1552.6\left(\mathrm{M}^{+},+3 \mathrm{PF}_{6}{ }^{-}\right), 703.2\left(\mathrm{M}^{2+},+2 \mathrm{PF}_{6}{ }^{-}\right), 372.2$ $\left(\mathrm{M}^{3+}\right), 279.1\left(\mathrm{M}^{4+}\right)\left(\mathrm{C}_{66} \mathrm{H}_{76} \mathrm{~N}_{4} \mathrm{O}_{12}{ }^{4+}\right.$ requires 1117.33).

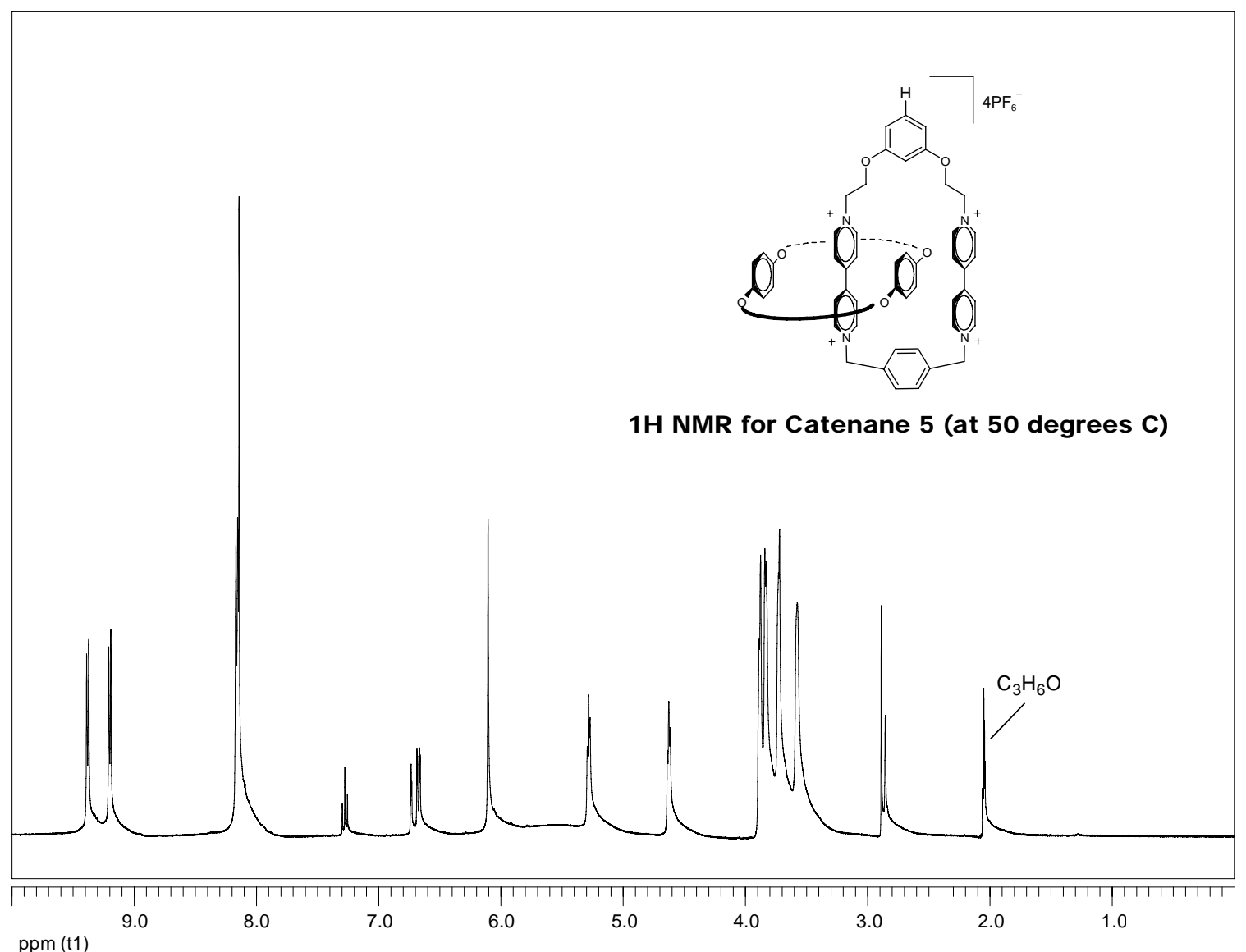

Catenane 6. 1,3-Bis-(2-(4,4'-dipyridinium)-ethoxy)-5-di-p-tolylmethyl-benzene dihexafluorophosphate (15b) $(0.140 \mathrm{~g}, 0.146 \mathrm{mmol})$ and BPP34C10 (0.125 g, 0.233 mmol) were combined and dissolved in $\mathrm{CH}_{3} \mathrm{CN}(15 \mathrm{ml})$. This solution was allowed to stir for 10 minutes at which point $\alpha, \alpha$ '-dibromo-p-xylene $(0.051 \mathrm{~g}, 0.192 \mathrm{mmol})$ was added and the reaction vessel sealed with a septa. This red solution stirred 4 days under ambient conditions after which time the solvent was removed in vacuo. The catenane was purified and after drying, $55 \mathrm{mg}$ (19\%) of red solid was recovered. ${ }^{1} \mathbf{H}$ NMR 
$\left(\mathrm{C}_{3} \mathrm{D}_{6} \mathrm{O}, 400 \mathrm{MHz}\right): \delta 9.39(\mathrm{~d}, \mathrm{~J}=6.7 \mathrm{~Hz}, 4 \mathrm{H}), 9.16(\mathrm{~d}, \mathrm{~J}=6.7 \mathrm{~Hz}, 4 \mathrm{H}), 8.16(\mathrm{~m}, 12 \mathrm{H}), 7.14$ (d, J=7.9 Hz, 4H), 7.05 (d, J=8.2 Hz, 4H), 6.60 (t, J=2.1 Hz, 1H), 6.51 (d, J=2.1 Hz, 2H), $6.11(\mathrm{~s}, 4 \mathrm{H}), 5.49$ (s, 1H), $5.24(\mathrm{t}, \mathrm{J}=4.2 \mathrm{~Hz}, 4 \mathrm{H}), 4.51$ (t, J=4.2 Hz, 4H), 3.86 3.52 (m, 32H), $2.30(\mathrm{~s}, 6 \mathrm{H}) .{ }^{13} \mathrm{C}$ NMR $\left(\mathrm{C}_{3} \mathrm{D}_{6} \mathrm{O}, 75 \mathrm{MHz}\right): \delta 158.7,151.8,147.8,146.3,145.1$, $140.8,136.5,135.8,131.2,129.1,129.0,126.3,125.7,114.4,107.1,102.9,70.3,70.1$, 69.8, 67.4, 65.8, 64.9, 60.8, 56.3, 54.6, 20.2. MS (ESI): $\mathrm{m} / \mathrm{z} 327.9\left(\mathrm{M}^{4+}\right), 485.6\left(\mathrm{M}^{+}\right.$, $\left.+\mathrm{PF}_{6}{ }^{-}\right), 800.9\left(\mathrm{M}^{2+},+\mathrm{PF}_{6}^{-}\right)\left(\mathrm{C}_{81} \mathrm{H}_{90} \mathrm{~N}_{4} \mathrm{O}_{12}{ }^{4+}\right.$ requires 1361.65).

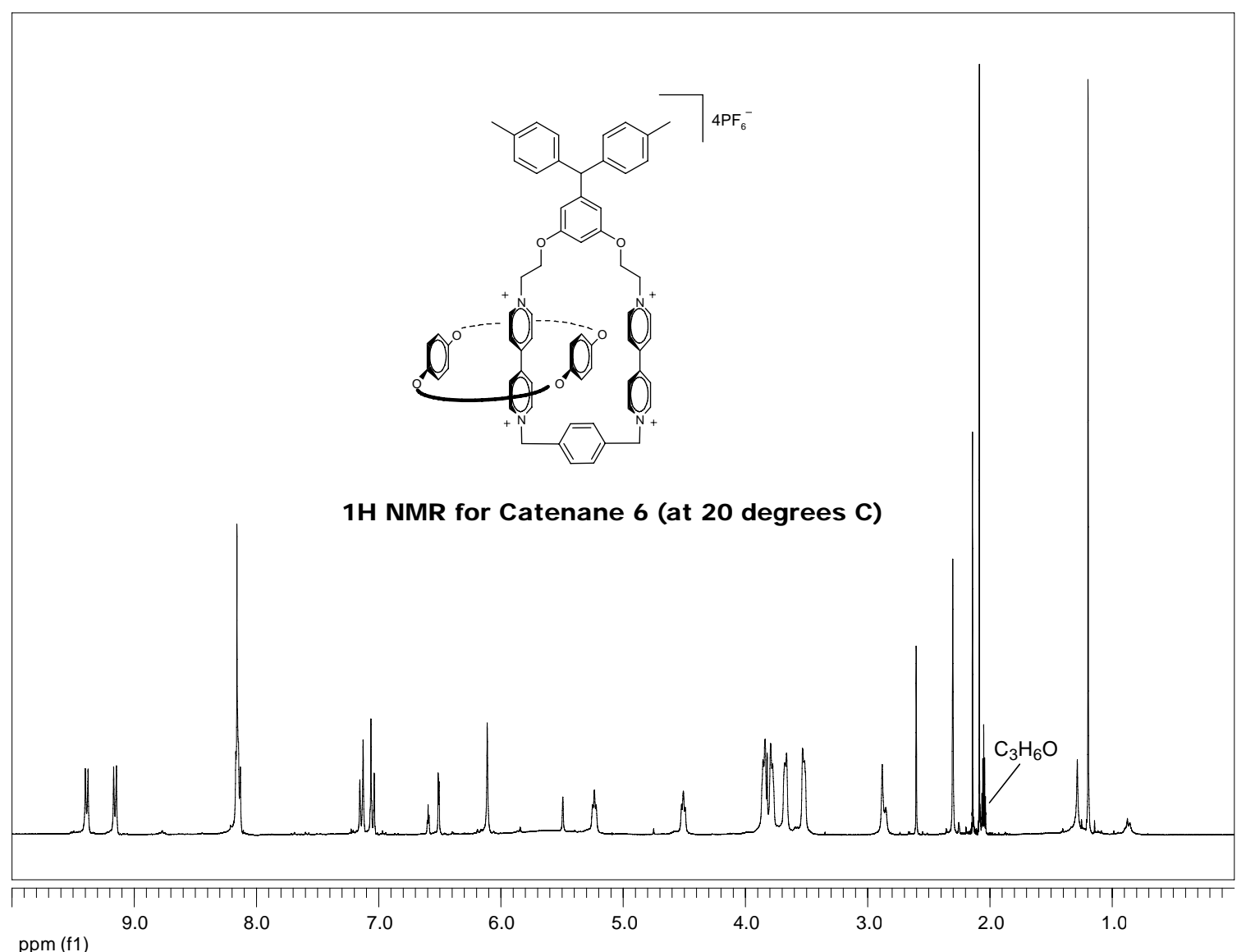

ppm (f1) 


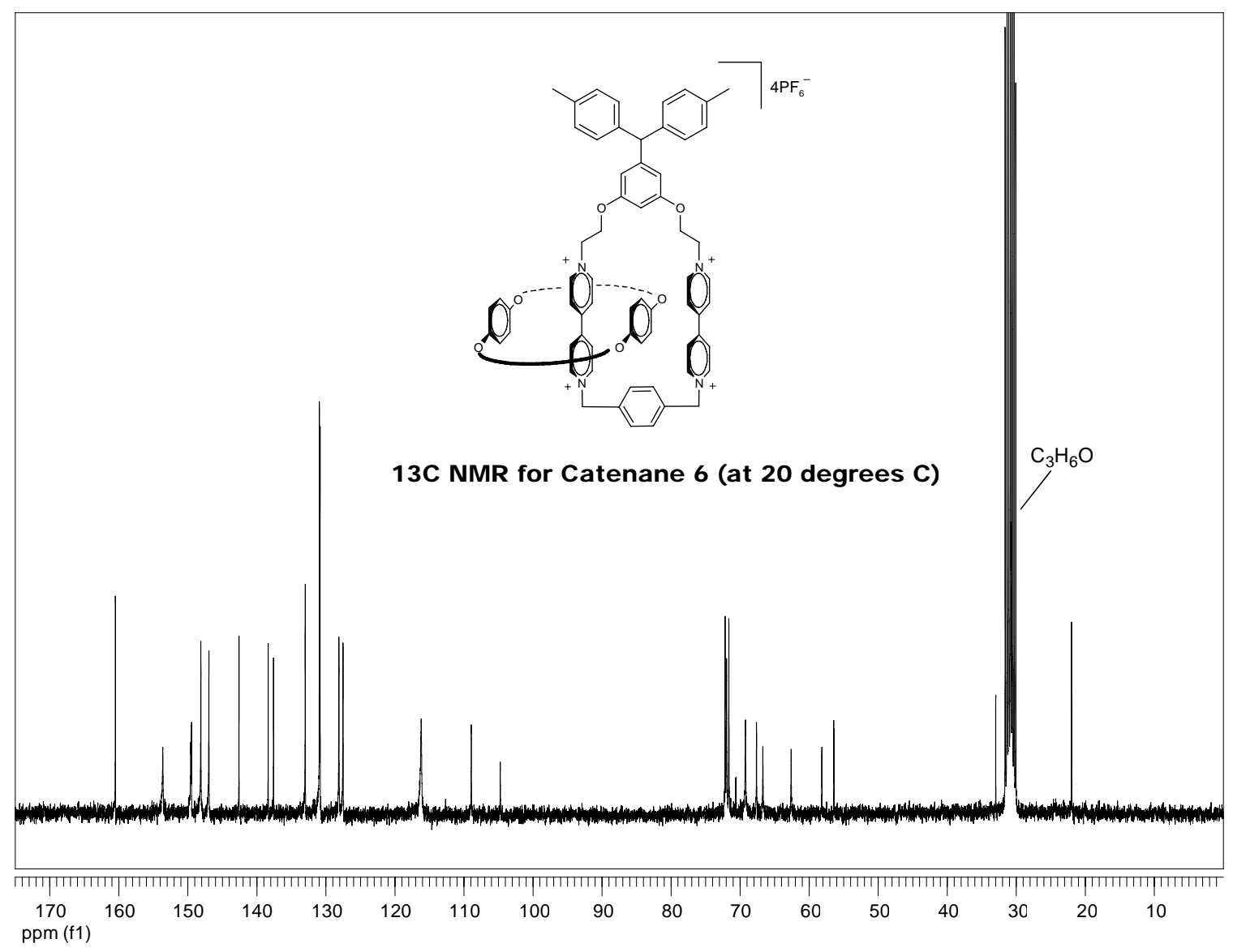

\section{VT ${ }^{1} \mathrm{H}-\mathrm{NMR} 400 \mathrm{MHz}$ Spectra of Catenane 2:}

Full spectra at temperatures $+20^{\circ} \mathrm{C}$ and $-40^{\circ} \mathrm{C}$ are provided for reference. The stacked plot (sweep width 9.8 to $8.8 \mathrm{ppm}$ ) of Catenane 2 seen below is typical of the $\mathrm{VT}{ }^{1} \mathrm{H}$ NMR spectra observed for the catenanes. For Catenane 2 protons of the dipyridinium rings were observed to coalesce at $-12^{\circ} \mathrm{C}($ doublet $\mathrm{A})$ and $-19^{\circ} \mathrm{C}$ (double $\left.\mathrm{B}\right)$. 


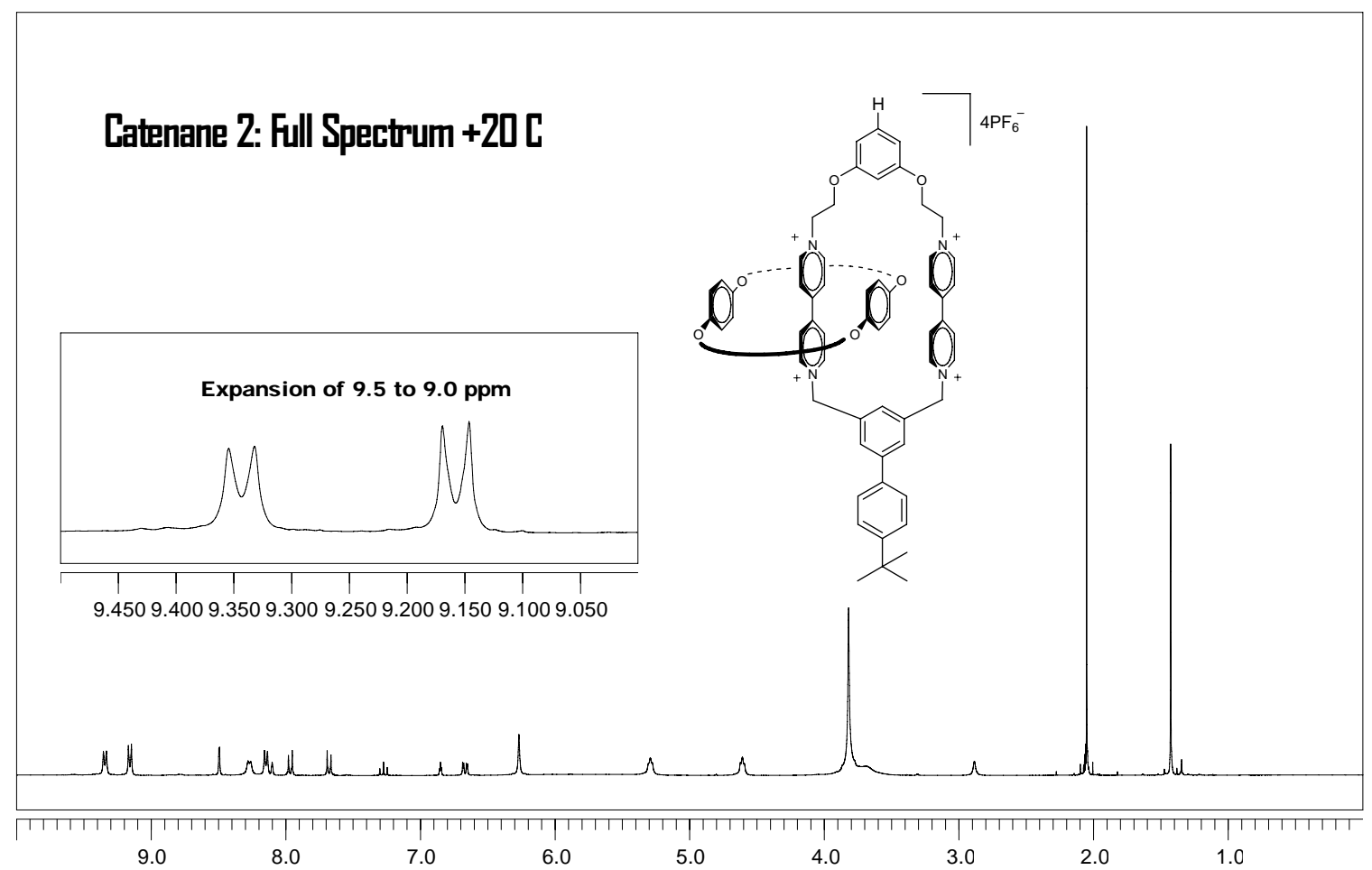

ppm (t1)

\section{Catenane 2: Full Spectrum -40 C}
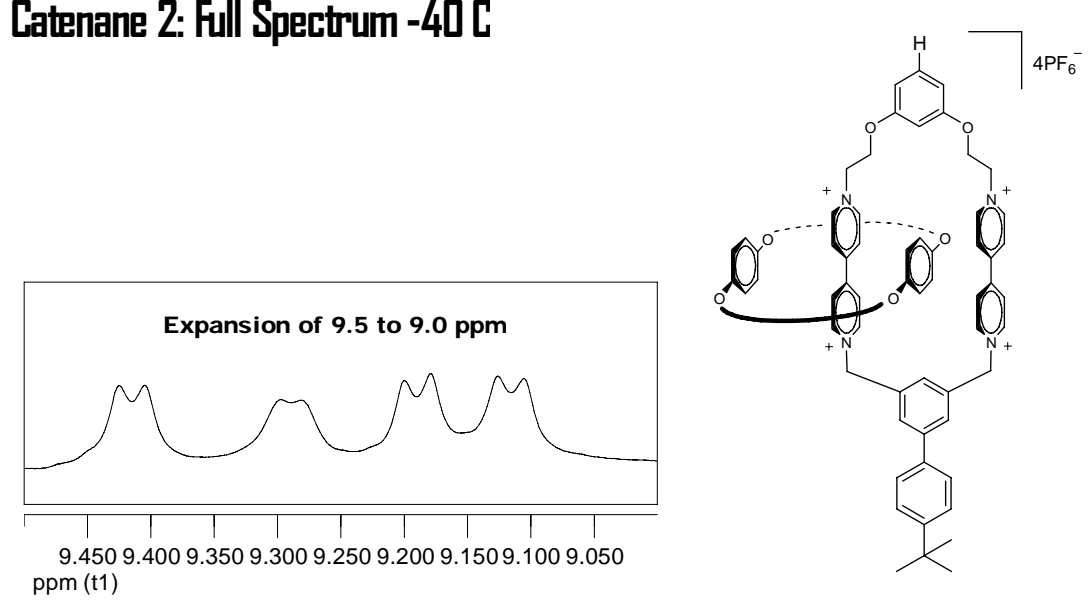
ppm (t1)
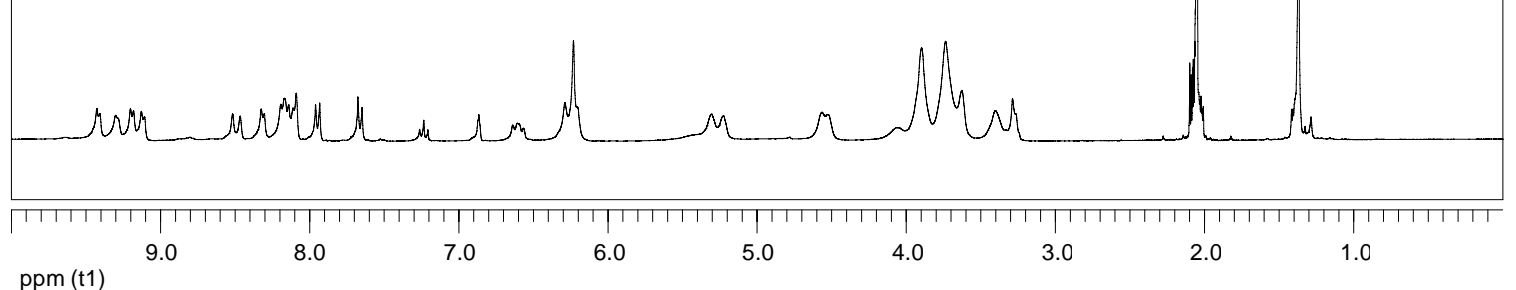


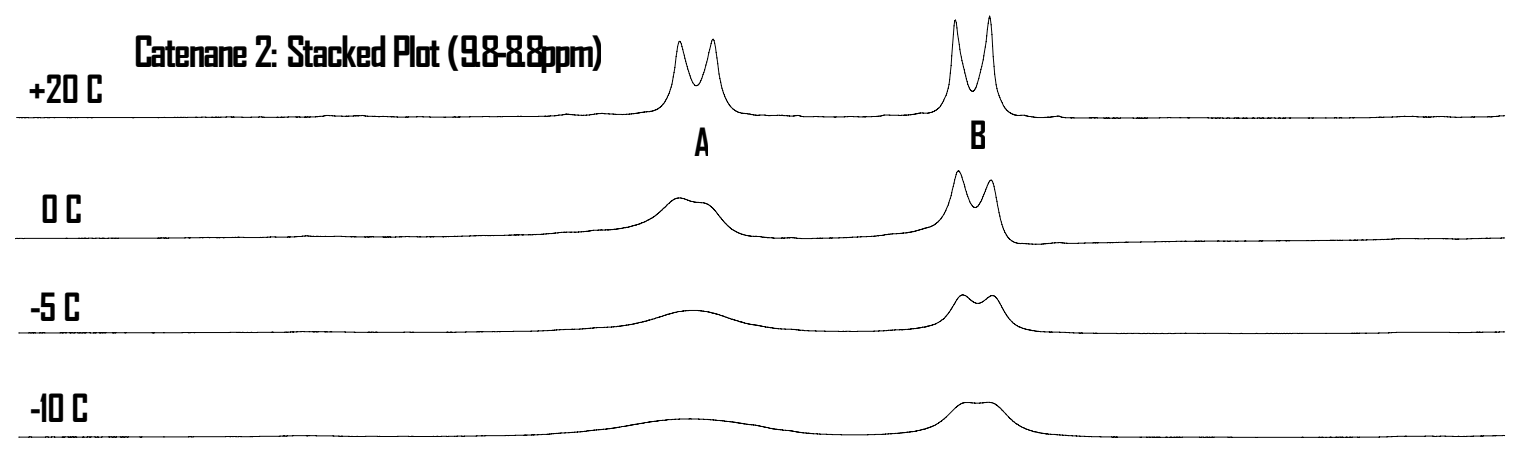

-15 C

$-20 \mathrm{C}$

$-25[$

-30 C

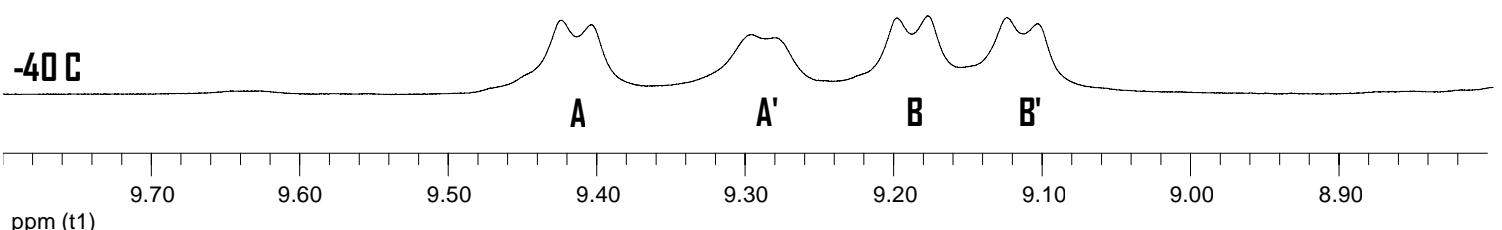

ppm (t1)

${ }^{1}$ Brockmann, H.; Kluge, F.; Muxfeldt, H. Chem. Ber. 1957, 90, 2302-2318

${ }^{2}$ Müller, W.; Lowe, D. A.; Neijt, H.; Urwyler, S.; Herrling, P. L.; Blaser, D.; Seebach, D. Helv. Chim. Acta 1992, 75, 855-864.

${ }^{3}$ Helgeson, R.C; Tarnowski, T.L.; Timko, J.M.; Cram, D.J. J. Am. Chem. Soc. 1977, 99, 6411-6418 